\title{
Localization versus delocalization in chiral single component conductors of gold bis(dithiolene) complexes
}

Diana G. Branzea, ${ }^{\dagger}$ Flavia Pop, ${ }^{\dagger}$ Pascale Auban-Senzier, ${ }^{\ddagger}$ Rodolphe Clérac, ${ }^{\# \text {, }}$ Pere Alemany, ${ }^{*, l}$ Enric Canadell, ${ }^{, \S}$ and Narcis Avarvari*, ${ }^{\dagger}$

† Université d'Angers, CNRS, Laboratoire de Chimie et Ingénierie Moléculaire CIMA UMR 6200, UFR Sciences, Bât. K, 2 Bd. Lavoisier, 49045 Angers, France Fax: (+33)02 417354 05; Tel: (+33)02 41735084.

E-mail: narcis.avarvari@univ-angers.fr

‡ $\quad$ Laboratoire de Physique des Solides, CNRS UMR 8502, Univ. Paris-Sud, Université Paris-Saclay, 91405 Orsay, France

\# $\quad$ CNRS, CRPP, UPR 8641, F-33600 Pessac, France

ฯ Univ. Bordeaux, CRPP, UPR 8641, F-33600 Pessac, France

" Departament de Ciència de Materials i Química Física i Institut de Química Teórica i Computacional (IQTCUB), Universitat de Barcelona, Martí i Franquès 1, 08028 Barcelona, Spain

$\S \quad$ Institut de Ciència de Materials de Barcelona (CSIC), Campus de la UAB, E-08193 Bellaterra, Spain 
ABSTRACT: The first examples of chiral single component conductors are reported. Both $(S, S)$ and $(R, R)$ enantiomers of 5,6-dimethyl-5,6-dihydro-1,4-dithiin-2,3-dithiolate (dm-dddt) ligand have been used to prepare anionic metal bis(dithiolene) complexes formulated as ([(n$\left.\mathrm{Bu})_{4} \mathrm{~N}\right]\left[\mathrm{M}(\mathrm{dm}-\mathrm{dddt})_{2}\right](\mathrm{M}=\mathrm{Au}, \mathrm{Ni})$, which are isostructural according to single crystal X-ray analysis. The methyl substituents are oriented either in axial or equatorial positions in the two independent complexes, which do not engage in short intermolecular S $\cdots S$ contacts. Single crystal transport measurements indicate semiconducting behavior for the anionic radical $\mathrm{Ni}$ complexes, with low room temperature conductivity values and high activation energies. Electrocrystallization experiments provided neutral [M(dm-dddt $\left.)_{2}\right](\mathrm{M}=\mathrm{Au}, \mathrm{Ni})$ complexes. The neutral radical gold compounds show intermolecular S $\cdots S$ interactions in the solid state giving rise to layers interconnected through weak $\mathrm{C}-\mathrm{H} \cdots \mathrm{S}$ hydrogen bonds. The most peculiar structural feature concerns a dissymmetry between the two dithiolene moieties, while the nickel counterpart is symmetric. Single crystal resistivity measurements show temperature activated behavior for the open-shell gold complexes, with room temperature conductivity values of $0.02-0.04 \mathrm{~S} \cdot \mathrm{cm}^{-1}$ and activation energies strongly influenced by hydrostatic pressure. A thorough theoretical study on nickel anion radical and gold neutral radical bis(dithiolene) complexes applied to the chiral complexes $\left[\mathrm{M}(\mathrm{dm}-\mathrm{dddt})_{2}\right]\left(\mathrm{M}=\mathrm{Au}, \mathrm{Ni}^{-}\right)$and to a series of previously reported compounds addressed the issue of symmetry versus asymmetry from an electronic coupling perspective between the two dithiolene ligands. It results that neutral gold complexes with dithiolene ligands without extended delocalization are Class II mixed-valent compounds in the Robin and Day classification, presenting an inherent tendency towards asymmetric structures, which can be however modulated by the intermolecular organization in the solid state. 


\section{INTRODUCTION}

Metal-dithiolene complexes have been extensively studied in recent decades as candidates for molecule-based functional materials due to their propensity to form air stable charged (mostly anionic) and neutral dia- or paramagnetic complexes with various metal atoms such as $\mathrm{Ni}, \mathrm{Pd}$, $\mathrm{Pt}, \mathrm{Au}, \mathrm{Cu}, \mathrm{Co}$, etc. ${ }^{1}$ The optical properties, the charge of the complex and the electrochemical behaviour can be finely tuned by carefully choosing the metal and the substitution pattern of the dithiolene ligands. The square-planar geometry of metalbis(dithiolene) complexes is particularly favourable for their stacking into columns, thus providing conducting materials in their anionic or neutral forms. ${ }^{2}$ For example, the first reported molecular superconductor based on metal-dithiolene complexes was obtained by association of TTF and [Ni(dmit $\left.)_{2}\right]$ (dmit = 1,3-dithiole-2-thione-4,5-dithiolate) in the charge transfer complex $(\mathrm{TTF})\left[\mathrm{Ni}(\mathrm{dmit})_{2}\right]_{2} .{ }^{3}$ Neutral conducting species are of special interest as they form the so-called "single component" conductors, which have been particularly developed with extended dithiolene ligands containing a tetrathiafulvalene (TTF) backbone, as here the electron density and the charge are delocalized over the entire TTF-dithiolate moiety. ${ }^{4}$ Accordingly, TTF-dithiolene based complexes exhibiting metallic behaviour such as $\left[\mathrm{Ni}(\mathrm{tmdt})_{2}\right]\left(\mathrm{tmdt}=\right.$ trimethylene-TTF-dithiolate), ${ }^{5}\left[\mathrm{Au}(\mathrm{tmdt})_{2}\right],{ }^{6}\left[\mathrm{Cu}(\mathrm{dmdt})_{2}\right](\mathrm{dmdt}=$ dimethyl-TTF-dithiolate), ${ }^{7}$ and even a superconducting transition in $\left[\mathrm{Ni}(\mathrm{hfdt})_{2}\right](\mathrm{hfdt}=$ bis(trifluoromethyl)-TTF-dithiolate) ${ }^{8}$ have been described in the last fifteen years. Conducting neutral metal-dithiolene complexes without a TTF backbone contain, with very few exceptions such as a molybdenum dmit cluster ${ }^{9}$ or $\left[\mathrm{Ni}(\mathrm{dmit})_{2}\right],{ }^{10}$ almost exclusively the $\mathrm{Au}(\mathrm{III})$ center, as upon one-electron oxidation of the anionic $\left[\mathrm{Au} \text { (dithiolene) }{ }_{2}\right]^{-}$precursor the neutral open-shell species is readily generated. Such neutral radical complexes include $\left[\mathrm{Au}(\mathrm{bdt})_{2}\right]$ (bdt $=$ benzene-1,2-dithiolate), ${ }^{11}\left[\mathrm{Au}(\alpha \text {-tpdt })_{2}\right]\left(\alpha\right.$-tpdt $=\alpha$-thiophene-dithiolate) ${ }^{12}$ $\left[\mathrm{Au}(\alpha \text {-EtMetpdt })_{2}\right] \quad\left(\alpha\right.$-EtMetpdt $=$ 4-ethyl-5-methyl-thiophene-2,3-dithiolate) ${ }^{13}$ and $\left[\mathrm{Au}\left(\mathrm{F}_{2} \mathrm{pdt}\right)_{2}\right]\left(\mathrm{F}_{2} \mathrm{pdt}=2 \text { 2,2-difluoropropylene-dithioethylene-dithiolate }\right)^{14}$ showing activated conductivity, together with $\left[\mathrm{Au}(\mathrm{Et} \text {-thiazdt })_{2}\right]$ (Et-thiazdt $=N$-ethyl-1,3-thiazoline-2-thione4,5-dithiolate) endowed with metal like conductivity under pressure. ${ }^{15}$

Moreover, much effort has been paid over the last fifteen years to introduce multifunctionality in the field of molecular conductors particularly based on TTF, ${ }^{16}$ and one such property that can trigger the emergence of new physical phenomena is chirality. ${ }^{17}$ Accordingly, the synergistic effect referred to as electrical magneto-chiral anisotropy (eMChA) effect, which arises when transport properties of a chiral conductor are measured under a parallel applied 
magnetic field, ${ }^{18}$ has been recently observed for enantiopure radical cation salts (DM-EDT$\mathrm{TTF})_{2} \mathrm{ClO}_{4}$ based on either of the $(R, R)$ or $(S, S)$ enantiomers of dimethyl-ethylenedithio-TTF (DM-EDT-TTF) precursor. ${ }^{19}$ While several families of chiral TTFs have been reported, ${ }^{20}$ together with chirality related properties such as different conductivity of racemic and enantiopure forms, ${ }^{21}$ chiroptical modulation, ${ }^{22}$ or self-assembly into helical aggregates, ${ }^{23}$ examples of chiral metal-dithiolene complexes are still rare in the literature, ${ }^{24,25,26}$ with those showing conducting behavior being even scarcer. ${ }^{27,28}$ Chirality has been introduced either in the structure of the ligand through bornyl-dithiolate ( $\mathrm{Ni}$ and $\mathrm{Au}$ complexes), ${ }^{24}$ cholesterol based dithiolate (Ni complexes), ${ }^{25} \mathrm{~N}$-2'-Ph-ethyl-thiazdt (Ni complexes), ${ }^{26}$ and 1,3-dioxolanetetrathiaethylene (diotte) (Ni complexes) ${ }^{27}$ units, or in the counterion as chiral ammonium ions in a series of anionic $\left[\mathrm{Ni}(\mathrm{dmit})_{2}\right]$ complexes, ${ }^{28}$ the last two systems showing semiconducting behavior.

Although tetramethyl-bis(ethylenedithio)-TTF (TM-BEDT-TTF, Chart 1) as $(S, S, S, S)$ enantiomer was the first reported example of enantiopure TTF, ${ }^{29}$ its constituting half 5,6dimethyl-5,6-dihydro-1,4-dithiin-2,3-dithiolate (dm-dddt) has never been used as ligand to the best of our knowledge.

\section{Chart 1}

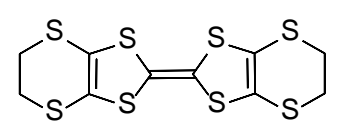

BEDT'TTF

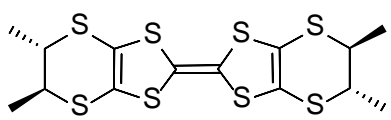

( $\left.S^{\prime} S^{\prime} S^{\prime} S\right)^{-}{ }^{-T M}{ }^{\top}$ BEDT"TTF

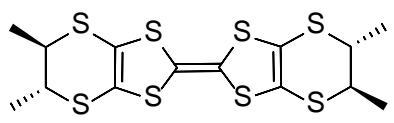

$\left(R^{\prime} R^{\prime} R^{\prime} R\right)^{-}$TM $^{-}$BEDT ${ }^{-T T F}$

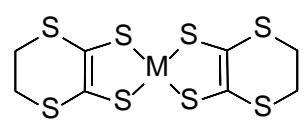

$M(d d d t){ }_{2}{ }^{\prime}=A^{u} \cdot \mathrm{Ni}$

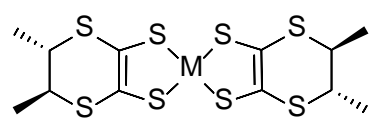

$\left[A^{U}\left(S^{\prime} S^{-} d^{-} d d d t\right)_{2}{ }^{1 a}\right.$ $\left[\mathrm{Ni}\left(\mathrm{S}^{\prime} S^{-} \mathrm{dm}^{-} \mathrm{dddt}\right)_{2]} \mathbf{2 a}^{\mathbf{a}}\right.$

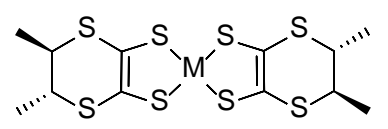

$\left[\mathrm{AU}^{\mathrm{U}}\left(R^{\prime} R^{-} \mathrm{dm}^{-} \mathrm{dddt}\right)_{2}\right] \mathbf{1 b}$ $\left[\mathrm{Ni}\left(R^{\prime} R^{-} \mathrm{dm}^{-} \mathrm{dddt}_{2}\right)_{2} \mathbf{2 b}\right.$

We describe herein the first enantiopure anionic $\left[\mathrm{M}(\mathrm{dm}-\mathrm{dddt})_{2}\right]^{-}(\mathrm{M}=\mathrm{Au}, \mathrm{Ni})$ complexes and their neutral $\left[\mathrm{M}(\mathrm{dm} \text {-dddt })_{2}\right]$ analogues (Chart 1) based on the dm-dddt ligand, together with their solid state structures and conducting properties. We particularly focus our study on the [Au(dm-dddt $)_{2}$ ] complexes as first chiral single component conductors, for which a combination of tight-binding band structure and DFT calculations on the solid and the isolated complex revealed a charge localization which was totally overlooked up to now, including in 
the achiral derivative $\left[\mathrm{Au}(\mathrm{dddt})_{2}\right]$ described almost 30 years ago. ${ }^{30}$ The interplay between localization versus delocalization is thoroughly discussed according to the nature of the ligand and the solid state structures of the neutral radical complexes through examples reported in the literature and compared to our newly synthesized chiral system. This study leads to new insights into the delicate balance of factors needing careful attention in the search for new single component conductors based on metal bis(dithiolene) complexes.

\section{RESULTS AND DISCUSSION}

Synthesis and solid state structures. The chiral monoanionic complexes 1a-b (Au) and 2a-b (Ni) have been synthesized by deprotection of enantiopure $(S, S)$ and $(R, R)$ dithiolone 3 , prepared according to the procedure described in the literature, ${ }^{21 c, 31}$ with sodium methanolate, followed by reaction with metal salts and cation exchange. This synthetic approach affords the complexes as crystalline salts with the tetra-n-butyl-ammonium (TBA) cation after aerial oxidation and recrystallization (Scheme 1 for the $(S)$ enantiomers).

\section{Scheme 1. Synthesis of enantiopure (TBA)[M(dm-dddt $\left.)_{2}\right]$ complexes}

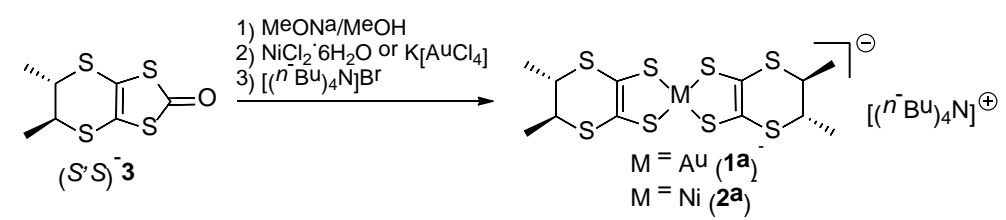

Circular dichroism (CD) spectra of monoanionic 1a-b and 2a-b show the expected mirror image relationship between the respective enantiomers (see Figures S1 and S2), with bands below $400 \mathrm{~nm}$ similar in sign and intensity to those found in the TM-BEDT-TTF donor. ${ }^{32}$ Additionally, weakly intense bands centered at $445 \mathrm{~nm}$ can be observed for the open-shell $\mathrm{Ni}$ complexes (TBA)(2a) and (TBA)(2b). The UV-vis spectra are also informative of the oxidation state of the complexes, as for the closed-shell Au complexes only high energy absorption bands below $320 \mathrm{~nm}$ are present, while the Ni complexes display a weakly intense band at $615 \mathrm{~nm}$, very likely due to a d-d transition, together with the typical intense NIR band at $1185 \mathrm{~nm}\left(\varepsilon=12800 \mathrm{dm}^{3} \cdot \mathrm{mol}^{-1} \cdot \mathrm{cm}^{-1}\right)$ (see Figures S3 and S4) arising from a HOMO-1 to SOMO transition. ${ }^{33}$

Cyclic voltammetry measurements show a pair of reversible oxidation processes for the gold complex (TBA)(1a) at +0.32 and $+0.79 \mathrm{~V}$ vs SCE corresponding to the formation of the neutral 1a and oxidized (1a) ${ }^{+}$species (Table S1 and Figure S5). The nickel complex 
(TBA)(2a) shows, besides the two reversible oxidation processes occurring at $-0.03 \mathrm{~V}$ and +0.92 vs SCE for the generation of neutral $\mathbf{2 a}$ and cationic $(\mathbf{2 a})^{+}$, a reversible reduction wave at $-0.72 \mathrm{~V}$ vs SCE corresponding to the formation of the diamagnetic dianion species $(2 \mathbf{a})^{2-}$. These measurements suggest that the neutral species of both Au and Ni complexes should be readily accessible by chemical or electrochemical oxidation.

Suitable single crystals of (TBA)(1a) and (TBA)(2a) for X-ray diffraction measurements have been grown by slow diffusion of hexane into $\mathrm{CH}_{2} \mathrm{Cl}_{2}$ solutions of the corresponding complexes, while cell determinations proved that (TBA)(1b) and (TBA)(2b) are isostructural with their respective enantiomers. Since the crystallographic analyses revealed that (TBA)(1a) and (TBA)(2a) are isostructural, only the structure for the paramagnetic Ni complex (TBA)(2a) will be discussed hereafter (see SI for details on the structure of (TBA)(1a)). The complexes crystallize in the triclinic non-centrosymmetric space group $P 1$ with two independent bis(dithiolene) anion complexes and TBA cations in general positions in the asymmetric unit. Bond lengths and angles (Table 1) are in the typical range for such anionic species and compare to those found in (TBA)[Ni(dddt) ${ }_{2}{ }^{30}$

Table 1. Selected bond lengths $(\AA)$ and angles $\left({ }^{\circ}\right)$ in (TBA)(2a)

\begin{tabular}{llll}
\hline \multicolumn{4}{c}{ Bond lengths $(\AA)$} \\
Ni1-S2A & $2.136(2)$ & Ni2-S5B & $2.151(2)$ \\
Ni1-S5A & $2.143(2)$ & Ni2-S1B & $2.152(3)$ \\
Ni1-S6A & $2.147(2)$ & Ni2-S6B & $2.158(3)$ \\
Ni1-S1A & $2.154(2)$ & Ni2-S2B & $2.159(2)$ \\
C1A-C2A & $1.353(10)$ & C1B-C2B & $1.355(10)$ \\
C7A-C8A & $1.341(10)$ & C7B-C8B & $1.361(10)$ \\
S1A-C1A & $1.720(8)$ & S1B-C1B & $1.738(8)$ \\
S2A-C2A & $1.737(8)$ & S2B-C2B & $1.730(8)$ \\
S5A-C7A & $1.728(8)$ & S5B-C7B & $1.737(9)$ \\
S6A-C8A & $1.752(8)$ & S6B-C8B & $1.730(7)$ \\
\hline \multicolumn{5}{c}{ Angles ( $\left.{ }^{\circ}\right)$} \\
\hline S2A-Ni1-S5A & $178.27(14)$ & S5B-Ni2-S1B & $88.63(10)$ \\
S2A-Ni1-S6A & $88.63(9)$ & S5B-Ni2-S6B & $91.47(10)$ \\
S5A-Ni1-S6A & $91.34(9)$ & S1B-Ni2-S6B & $179.49(13)$ \\
S2A-Ni1-S1A & $91.19(9)$ & S5B-Ni2-S2B & $179.17(12)$ \\
S5A-Ni1-S1A & $88.88(9)$ & S1B-Ni2-S2B & $91.6(1)$ \\
S6A-Ni1-S1A & $178.52(13)$ & S6B-Ni2-S2B & $88.3(1)$ \\
\hline
\end{tabular}

The coordination geometry of the metal ions ( $\mathrm{Ni}$ and $\mathrm{Au}$ ) is, as expected, square planar. Interestingly, the difference between the two crystallographically independent complexes mainly resides on the orientation of the methyl substituents of the dihydro-dithiine rings, which are either all-axial (Ni1) or all-equatorial (Ni2) (Figure 1). 

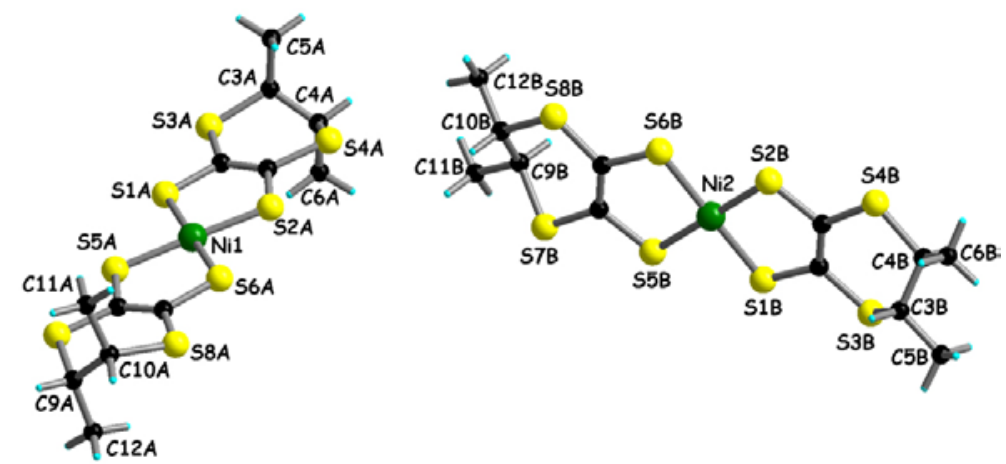

Figure 1. View of the two independent $\left[\mathrm{Ni}(S, S \text {-dm-dddt })_{2}\right]$ anionic complexes in the solid state structure of (TBA)(2a) together with the atom numbering scheme. $\mathrm{H}$ atoms are shown in cyan color. TBA cations have been omitted for clarity.

The arrangement of the methyl substituents in the TM-BEDT-TTF donor (see Chart 1) and derived radical cation salts has been thoroughly discussed through theoretical and experimental investigations. While in gas phase and solution the all-axial conformer of neutral TM-BEDT-TTF is slightly more stable than the all-equatorial one, ${ }^{32}$ crystallization of the latter is more straightforward in the solid state, probably because of the more favorable packing involving shorter intermolecular S $\cdots$ S contacts, although in certain conditions the allax conformer has been also crystallized. ${ }^{34}$ The tendency to favor crystallization of the all-eq conformer is even more pronounced in radical cation salts, ${ }^{32,34}$ since the all-ax conformer has been only recently observed in a radical cation salt of TM-BEDT-TTF with a rhenium cluster, ${ }^{35}$ while in a few cases the mixed (ax,ax,eq,eq) conformation occurred. ${ }^{34,36,37}$ In the solid state structures of (TBA)(1a) and (TBA)(2a) the presence of bulky TBA cations very likely hampers close intermolecular S $\cdots \mathrm{S}$ contacts, as no stacking between complexes is observed in the packing, and thus favors crystallization of both all-ax and all-eq conformations. Indeed, the anionic complexes are isolated from each other and at the supramolecular level the architecture is sustained by a set of intermolecular $\mathrm{C}-\mathrm{H}_{\mathrm{TBA}} \cdots \mathrm{S}$ contacts ranging from 2.73 to $2.99 \AA$ (Figure 2 and in SI Figures S7-S8, Table S2 for (TBA)(2a), Figures S9-S10 and Tables S3-S4 for (TBA)(1a)). The ax and eq conformers alternate along the $(c-b)$ direction, being separated by TBA cations, as well as along $(b+c)$, while they form -ax-ax- and -eq-eq- chains along the $a$ direction (see SI), though without any short intermolecular S $\cdots$ S contact, as stated above. Consequently, in spite of the openshell electronic structure for the Ni complexes (TBA)(2a) and (TBA)(2b) one can expect neither good transport properties nor strong magnetic coupling for these radical anion metal dithiolene species (vide infra). 


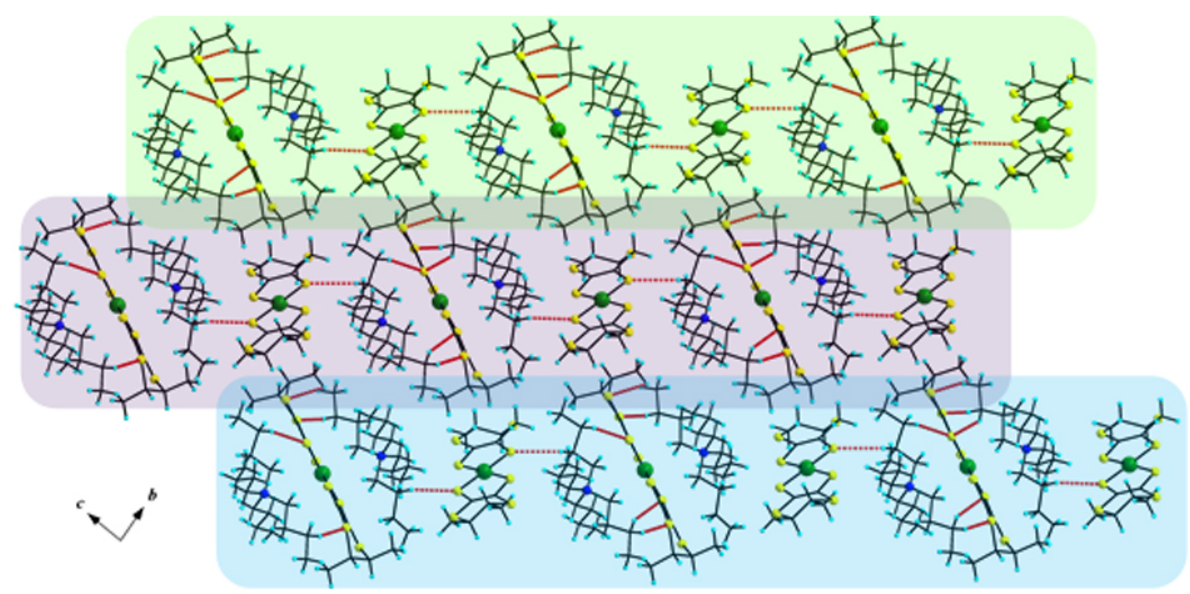

Figure 2. Crystal packing in (TBA)(2a): view in the $b c$ plane of the supramolecular layers, highlighted in different colors for clarity, with an emphasis on the $\mathrm{C}-\mathrm{H} \cdots \mathrm{S}$ contacts (red dotted lines) shorter than $3.0 \AA$.

As mentioned above, the gold complex (TBA)(1a) is isostructural with its nickel counterpart (TBA)(2a) (see SI). Note that, despite the presence of two independent molecules in the asymmetric unit, corresponding to the all-ax and all-eq conformers, the dithiolene moieties are equivalent, showing similar $\mathrm{C}-\mathrm{S}$ and $\mathrm{C}=\mathrm{C}$ bond lengths, as also observed in the structure of (TBA)(2a) (Table 1). For example, the four $\mathrm{C}=\mathrm{C}$ distances range from 1.324(14) to 1.345(13) in the structure of (TBA)(1a) (see Table S3 in SI).

Electrocrystallization of $\mathrm{Au}$ and $\mathrm{Ni}$ anionic precursors provided suitable single crystals for Xray diffraction analysis for neutral $\mathbf{1 b}(\mathrm{Au})$ and $\mathbf{2} \mathbf{b}(\mathrm{Ni})$, while cell determination for $\mathbf{1 a}$ clearly shown the same crystal parameters as for $\mathbf{1 b}$. Since $\mathbf{1 b}$ and $\mathbf{2 b}$ are isostructural, only the structure of the open-shell species $\mathbf{1 b}$ will be discussed hereafter (see SI for details on $\mathbf{2 b}$ ). The neutral complex crystallized in the triclinic non-centrosymmetric space group $P 1$, with one independent molecule in the asymmetric unit. The metal lies in a perfect square planar environment and the methyl groups are disposed in equatorial positions (Figure 3).

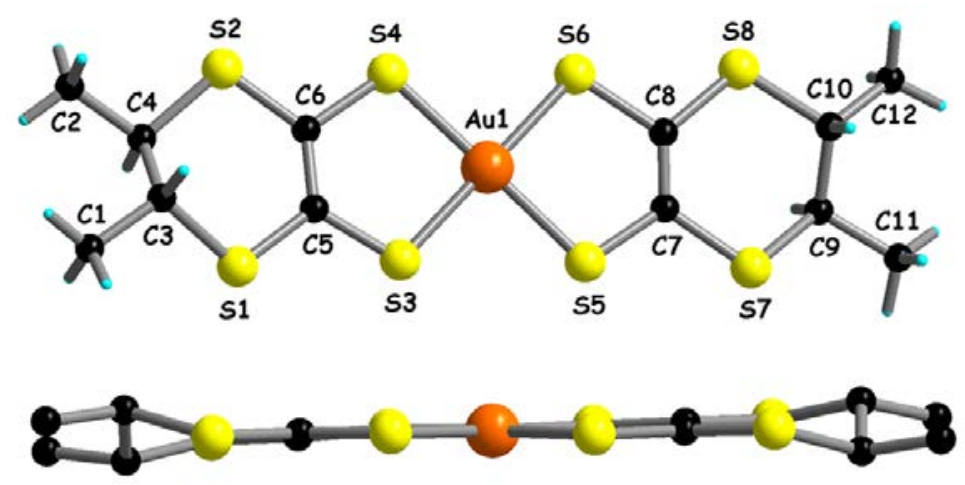

Figure 3. Structure of $\left[\mathrm{Au}(R, R \text {-dm-dddt })_{2}\right] \mathbf{1 b}$ with a top view along with the atom numbering scheme (top) and a side view (bottom). 
Interestingly, the two dithiolene rings show very different $\mathrm{C}=\mathrm{C}$ bond distances, i.e. 1.40(2) $\AA$ for C5-C6 and 1.30(3) Å for C7-C8 (Table 2), indicating a strong dissymmetry of the system.

Table 2. Selected bond lengths $(\AA)$ and angles $\left(^{\circ}\right)$ in $1 b$

\begin{tabular}{llll}
\hline \multicolumn{4}{c}{ Bond lengths $(\AA)$} \\
\hline S3-Au1 & $2.338(6)$ & C5-C6 & $1.40(2)$ \\
S4-Au1 & $2.333(6)$ & C7-C8 & $1.30(3)$ \\
S5-Au1 & $2.325(5)$ & C5-S3 & $1.727(17)$ \\
S6-Au1 & $2.333(6)$ & C6-S4 & $1.79(2)$ \\
& & C7-S5 & $1.76(2)$ \\
\multicolumn{4}{c}{ Angles ( $\left.{ }^{\circ}\right)$} \\
\hline S5-Au1-S4 & $178.9(3)$ & S3-Au1-S6 & $179.1(3)$ \\
S5-Au1-S6 & $88.5(2)$ & S5-Au1-S3 & $91.58(19)$ \\
S4-Au1-S6 & $91.97(19)$ & S4-Au1-S3 & $87.9(2)$ \\
\hline
\end{tabular}

A similar situation was encountered almost thirty years ago for the achiral version of $\mathbf{1 b}$, namely $\left[\mathrm{Au}(\mathrm{dddt})_{2}\right]$, for which the authors noticed at that time that: "The bond lengths are apparently asymmetric, which is probably unreal since they have large standard deviations...At the present moment we do not know the cause for this problem...”. ${ }^{30}$ Puzzled by this unexpected feature, we measured several crystals of $\mathbf{1 b}$ at variable temperatures, yet the dissymmetry between the two dithiolene units persisted. We have then decided to undertake a theoretical study on a series of neutral [Au(dithiolene) $)_{2}$ complexes reported in the literature to estimate whether such a dissymmetry is an inherent property of these species and to correlate it with their solid state structures and properties (vide infra).

At the supramolecular level, the complexes interact through S $\cdots S$ contacts $(3.67-3.80 \AA)$ along the $c$-direction forming step-chains, which further interact laterally along the $a$-direction by additional S $\cdots$ S contacts (3.65 - $3.99 \AA$ ) (Figure 4 and Table S5). The resulting layers are interconnected by weak C-H $\cdots$ S hydrogen bonding interactions (Figure S11 and Table S6). 


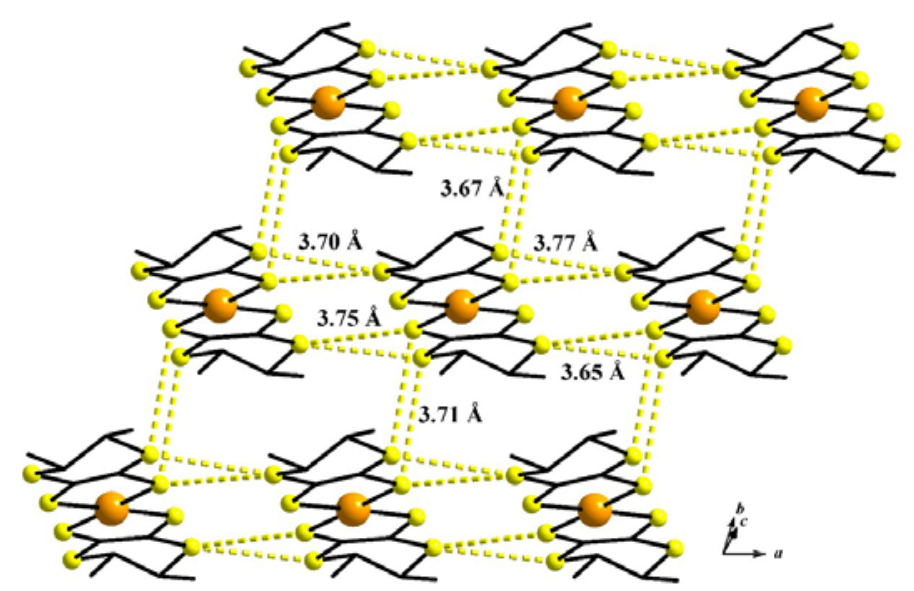

Figure 4. Crystal packing in $\mathbf{1 b}$ with an emphasis on the layer formed by S $\cdots \mathrm{S}$ contacts highlighted as yellow dotted lines.

As mentioned above the neutral gold and nickel complexes are isostructural, but, in contrast to $\left[\mathrm{Au}(R, R \text {-dm-dddt })_{2}\right] \mathbf{1 b}$, the two dithiolene moieties are symmetric in [Ni(R,R-dm-dddt $\left.)_{2}\right]$ 2b, as attested by the C=C bond distances, i.e. 1.389(6) $\AA$ for C5-C6 and 1.380(6) for C7-C8 (see Figures S12-S13 and Table S7 in SI for structural details on 2b), which represents a most peculiar feature (vide infra). The metal ion lies in a square planar environment, with only a very slight twist distortion of $3.8^{\circ}$ towards a tetrahedral geometry. The packing resembles to that observed in $\mathbf{1 b}$, with formation of chains along the $c$-direction, without any intrachain intermolecular S $\cdots S$ distance below $4.0 \AA$ A. These chains interact laterally through $\mathrm{S} \cdots \mathrm{S}$ contacts ranging between 3.68 and $3.84 \AA$.

Conducting properties of the open-shell species. The anionic nickel complexes (TBA)(2a) and (TBA)(2b) together with the neutral gold complexes $\mathbf{1 a}$ and $\mathbf{1 b}$ possess an unpaired electron and thus are susceptible to show sizeable transport properties. When considering the solid state structures of the Ni complexes, showing practically isolated molecules, one can expect at most activated conductivity with rather high resistivity values. This assumption is strongly supported by magnetic susceptibility measurements on a polycrystalline sample of (TBA)(2b), in agreement with the presence of isolated $S=1 / 2$ spin carriers $(C=0.40(1)$ $\mathrm{cm}^{3} \cdot \mathrm{K} \cdot \mathrm{mol}^{-1}$ and $g=2.06(2)$ ) which establish very weak antiferromagnetic interactions (on the basis of a Curie-Weiss paramagnetic behavior with $\theta=-1.0(1) \mathrm{K}$, Figures S14-S15). The temperature dependent single crystals resistivity show indeed a semiconducting behavior for (TBA)(2a) and (TBA)(2b), with room temperature conductivities of the order of 1-3 10 $\mathrm{S} \cdot \mathrm{cm}^{-1}$ and activation energies of $4100-4440 \mathrm{~K}(0.353-0.383 \mathrm{eV})$ (Figure S16). The layer type structure of the neutral gold complexes 1a-b is more favorable for extended electron 
delocalization, as is generally the case with single component conductors. Quite surprisingly, single crystal transport measurements on the two enantiomers $\mathbf{1 a}$ and $\mathbf{1 b}$ reveal rather low room temperature conductivity values of $0.02-0.04 \mathrm{~S} \cdot \mathrm{cm}^{-1}$ and semiconducting behaviors with large activation energy (1660 K $(0.143 \mathrm{eV})$ for $\mathbf{1 b}$, Figure 5).

Applying hydrostatic pressure leads to an exponential increase of the conductivity at room temperature (Figure S17) as expected for a semiconductor with an activation energy which varies linearly with pressure. At the same time, the temperature dependence of the resistivity still remains in an activated regime with a rapid decrease of the activation energy, down to $330 \mathrm{~K}(0.03 \mathrm{eV})$ at $11 \mathrm{kbar}$. However, the measurement was always performed in two points that includes the contribution of the contact resistance, no more negligible when the sample resistance decreases under pressure.

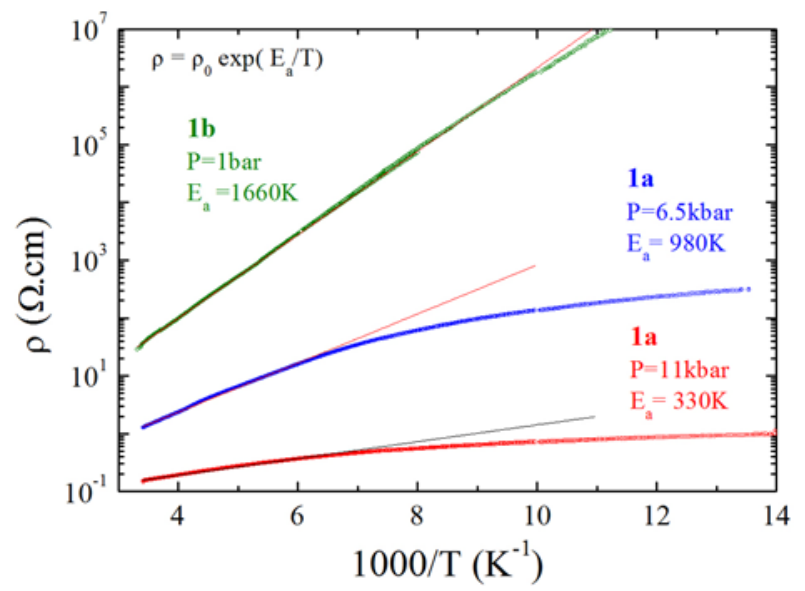

Figure 5. Temperature dependence of the electrical resistivity, $\rho$, plotted as log $\rho$ versus the inverse temperature, for single crystals of $\mathbf{1 a}$ at different applied pressures and $\mathbf{1 b}$ at ambient pressure. The lines are the fit to the data giving the activation energy.

As already mentioned, enantiomeric $\left[\mathrm{Au}(S, S-\mathrm{dm} \text {-dddt })_{2}\right] \mathbf{1 a}$ and $\left[\mathrm{Au}(R, R \text {-dm-dddt })_{2}\right] \mathbf{1 b}$ represent the first examples of chiral single component conductors, therefore, when considering the two dimensional arrangement of the neutral complexes in the solid state, one could have expected higher conductivity values and possibly a transition to a metallic state under pressure. Is this behavior related to the structural asymmetry of the complexes observed herein? In order to address this issue we have undertaken an in-depth theoretical study aiming at evaluating the intrinsic nature of such asymmetry in the more general context of anion radical $\mathrm{Ni}$ and neutral radical Au bis(dithiolene) complexes, with a special focus on the latter as they form the important family of single component conductors. 


\section{Relationship between the crystal structure, electronic structure and transport properties}

of $\left[\mathrm{Au}(\mathrm{dm}-\mathrm{dddt})_{2}\right] 1 \mathrm{a}-\mathrm{b}$ and related materials.

A. Nature of the SOMO $\cdots$ SOMO interactions in the solid. The singly occupied molecular orbital (SOMO) and the next lowest doubly occupied molecular orbital (SOMO-1) of neutral gold dithiolenes have been reported ${ }^{4,14,38}$ to be very similar to the LUMO and HOMO of BEDT-TTF, respectively, except for the replacement of a small contribution of the Au $d_{x y}$ orbital for the central $\mathrm{C}=\mathrm{C} \pi$-type contribution in BEDT-TTF. However, because of the relatively small participation of the $A u d_{x y}$ orbital the energy separation between these two orbitals is relatively small. Consequently, an interesting feature of gold dithiolene based solids is the possibility that the bands built from the SOMO, which are partially filled, may overlap with those originating from the SOMO-1. When this occurs, these systems may exhibit the so-called two-band behavior. ${ }^{38,39}$ The relationship between the crystal structure and the possibility of such overlap has been discussed for several of these systems. ${ }^{4,14,15 a}$
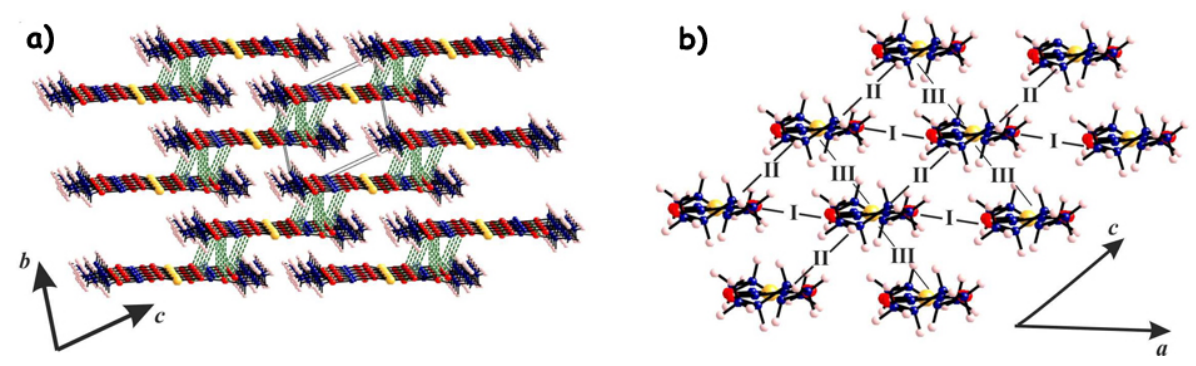

Figure 6. a) View of the crystal structure of $\mathbf{1 b}$ approximately along the $a$-direction where S $\cdots \mathrm{S}$ intermolecular contacts smaller than $4.0 \AA$ are shown as dashed green lines. b) Step-chain layer where the three different intermolecular interactions are noted.

As shown in Figure 6a, which is a perspective view approximately along $a$ where the short intermolecular S $\cdots \mathrm{S}$ contacts have been emphasized, the crystal structure of $\mathbf{1 b}$ is built from a series of step-chains along the $c$-direction. These step-chains do not make short S $\cdots$ S contacts along the interchain direction $b$, but are connected through lateral S $\cdots \mathrm{S}$ contacts along the $a$ direction. Consequently, as far as the S $\cdots S$ contacts are concerned, the crystal structure of $\mathbf{1 b}$ can be considered as containing layers of parallel step-chains, i.e. step-layers shown in Figure 6b, kept together through interlayer hydrogen bonds. These step-layers contain three different intermolecular interactions: those along a step-chain (II) and those coupling these chains either through side-by-side (I) or on-top (III) type contacts. The calculated extended Hückel band structure for the present compound is shown in Figure 7. Note the nil dispersion along 
$b^{*}$, that is consistent with the description highlighted in Figure $6 a$ as far as the SOMO $\cdots$ SOMO interactions are concerned. The SOMO and SOMO-1 bands are well separated and both are quite narrow. Consequently, a two-band behavior can be discarded and the electrons in the present compound are predicted to be localized and as a consequence the system will exhibit an activated conductivity in agreement with our measurements. This conclusion is also supported by first principles DFT calculations for the solid that show also that the hypothetical metallic state is unstable with respect to electron localization leading to either ferromagnetic or antiferromagnetic states (see SI).
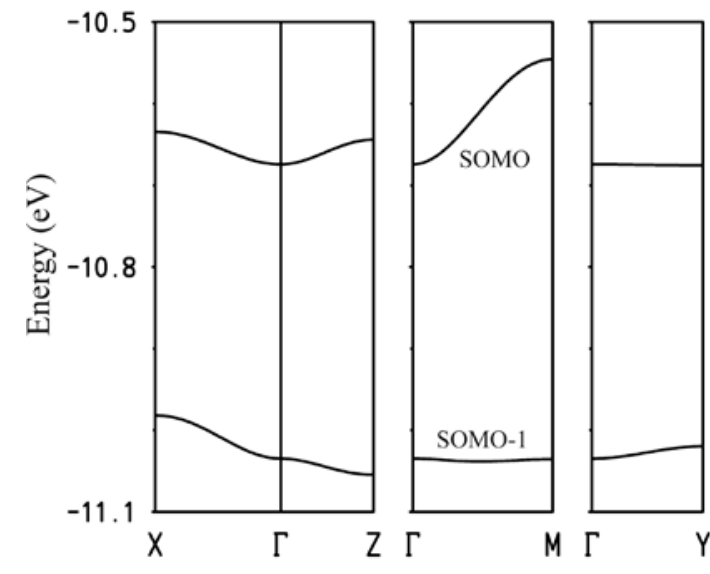

Figure 7. Calculated band structure for $\mathbf{1 b}$ at where $\Gamma=(0,0,0), X=\left(a^{*} / 2,0,0\right), Y=(0, b * / 2,0), Z=(0,0$, $\mathrm{c} * / 2)$ and $\mathrm{M}=(\mathrm{a} * / 2,0, \mathrm{c} * / 2)$.

The different S $\cdots$ S contacts shorter than $4.0 \AA$ for the three donor $\cdots$ donor interactions and the associated $\left|\beta_{\text {номо-номо }}\right|$ interaction energies, ${ }^{40}$ which are a measure of the strength of the HOMO $\cdots$ HOMO interactions (i.e. those determining the band structure near the Fermi level and, consequently, the transport properties of the salt) are reported in Table 3. Despite the presence of several short S $\cdots S$ contacts associated with interactions I and II, all the interactions are unexpectedly weak, thus leading to the slightly dispersive band structure of Figure 7 and the reason why the unpaired electron on each molecule should remain localized. Why are, however, these interactions so weak? Let us remind that other Au dithiolene neutral systems exhibiting not very different $S \cdots S$ intermolecular contacts and studied with exactly the same computational settings have been found to exhibit band dispersions associated with higher conductivities which are between two and three times larger ${ }^{14}$ than in the present case. 


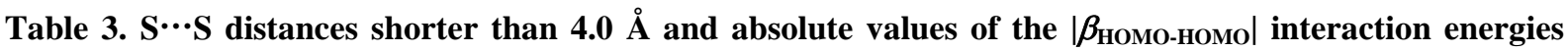
$(\mathrm{eV})$ for the different donor $\cdots$ donor interactions in $\mathbf{1 b}$

\begin{tabular}{|c|c|c|}
\hline Interaction & $\mathrm{S} \cdots \mathrm{S}(<4.0 \AA)$ & $\mid \beta$ номо-номо $(\mathrm{eV})$ \\
\hline $\mathbf{I}$ & $\begin{array}{c}3.659,3.706,3.753, \\
3.775,3.872,3.884\end{array}$ & 0.0291 \\
& $3.678,3.711,3.804$ & 0.0383 \\
\hline II & 3.994 & 0.0200 \\
\hline III & \multicolumn{2}{|c|}{} \\
\hline
\end{tabular}

The SOMO-SOMO interaction I is of lateral $\pi$-type and the corresponding S $\cdots S$ contacts are not short enough to lead to a sizeable interaction energy, while, in contrast, interactions II and III are of $\sigma$-type. However, interaction III is associated with a quite long S $\cdots S$ contact and thus it can only lead to a weak stabilization energy. More surprisingly, interaction II along the step-chains is also quite small, while the corresponding S $\cdots \mathrm{S}$ contacts are short enough to lead to an a priori strong interaction thanks to the very good $\sigma$-type overlap. As a matter of fact, these step-chain $\sigma$ interactions are among the strongest interactions in BEDT-TTF related salts and quite often dominate the shape of their band structure. ${ }^{41}$ To understand this surprising feature one must carefully examine the shape of the SOMO. Although this orbital in practically all neutral gold dithiolene complexes that we are aware of is equally (or almost equally) shared by the two thiolene moieties, ${ }^{4,14,38}$ in the present system it is concentrated in one of the two non-equivalent dithiolene moieties. As a matter of fact, the electron in the SOMO of $\mathbf{1 b}$ is 89 \% localized in the dithiolene moiety bearing the longer $\mathrm{C}=\mathrm{C}$ bond $(1.398$ vs. $1.298 \AA$ ) and the shorter C-S bonds (average values: 1.762 vs. $1.794 \AA$ ). Since interaction II is associated with contacts between one dithiolene ligand with large contribution to the SOMO and one dithiolene ligand with small contribution to the SOMO, the resulting orbital interaction is weak, despite the short S $\cdots S$ contacts and the good orbital orientation. Exactly the same reasoning applies to the SOMO-1 band since this orbital is localized just in the opposite way with respect to the SOMO. Thus, the localization of the SOMO in one of the two sides of the molecule is at the origin of the low conductivity of the system. Consequently, both structural and electronic effects are behind the weak interactions and low conductivity of the chiral neutral gold dithiolene complexes [Au(dm-dddt $\left.)_{2}\right] \mathbf{1 a - b}$.

Clearly, the possibility of an asymmetric distribution of the electron density in the SOMO may have a strong influence on the shape of the band structure and thus on the conducting properties of these systems. For this reason, a particularly important and interesting question is whether the intermolecular electronic localization (leading to the activated conductivity) is triggered by an intrinsic intramolecular localization in the individual mixed-valence neutral 
dithiolene complex or if it is due to some asymmetry in the packing forces in the crystal. When neither of these two factors is at work, the metal bis(dithiolene) system will exhibit equivalent (or nearly equivalent) ligands and they will most likely crystallize in centrosymmetric space groups with the complex located on an inversion center. Since the localization vs. delocalization dilemma has been completely ignored up to now in the search for new single component molecular conductors, in the following sections we undertake an in-depth analysis of this issue.

B. Intramolecular localization vs. delocalization in molecular models. Let us now try to identify the conditions for which a metal bis(dithiolene) compound $\left[M(D T)_{2}\right]^{n},(M=A u, n=$ $0 ; \mathrm{M}=\mathrm{Ni}, \mathrm{n}=-1$; DT: dithiolene ligand) with a single unpaired electron prefers a distorted structure that leads to a localization of the SOMO in one part of the molecule. The other system of interest in the field of molecular conductors for which we are aware, where $\mathrm{C}=\mathrm{C}$ bonds differ by as much as $0.07 \AA$, just slightly less than in $\mathbf{1 b}$, is [Au(dddt) $\left.{ }_{2}\right]^{30}$ the achiral version of 1. In that case, extended Hückel calculations showed that the SOMO is about $76 \%$ centered on the dithiolene fragment with the longer $\mathrm{C}=\mathrm{C}$ bond. On the other hand, it is also known that changing $\mathrm{Au}$ for the isoelectronic formally [Ni] ${ }^{-}$in $\mathbf{1 b}$ or [Au(dddt) ${ }_{2}$ leads to isoelectronic $\left[\mathrm{Ni}(\mathrm{DT})_{2}\right]^{-}$anions with symmetric structures where the SOMO is totally delocalized over the two dithiolene units. Thus we will first use several molecular models to try to shed some light on the driving force towards an intramolecular electronic localization in an isolated molecule of such type. Later we will consider the possible influence of intermolecular interactions on this localization process. Two main questions will be considered: (i) the influence of the metal linking the two organic moieties (Au or Ni), and (ii) the nature of the ligand. For this purpose we have investigated the electronic structure of fourteen compounds resulting from using either $\mathrm{Au}$ or $\mathrm{Ni}$ to link two equivalent dithiolene fragments taken from the list of seven cases detailed in Figure 8, providing either [Au(DT) $\left.)_{2}\right]$ or $\left[\mathrm{Ni}(\mathrm{DT})_{2}\right]^{-}$complexes. 


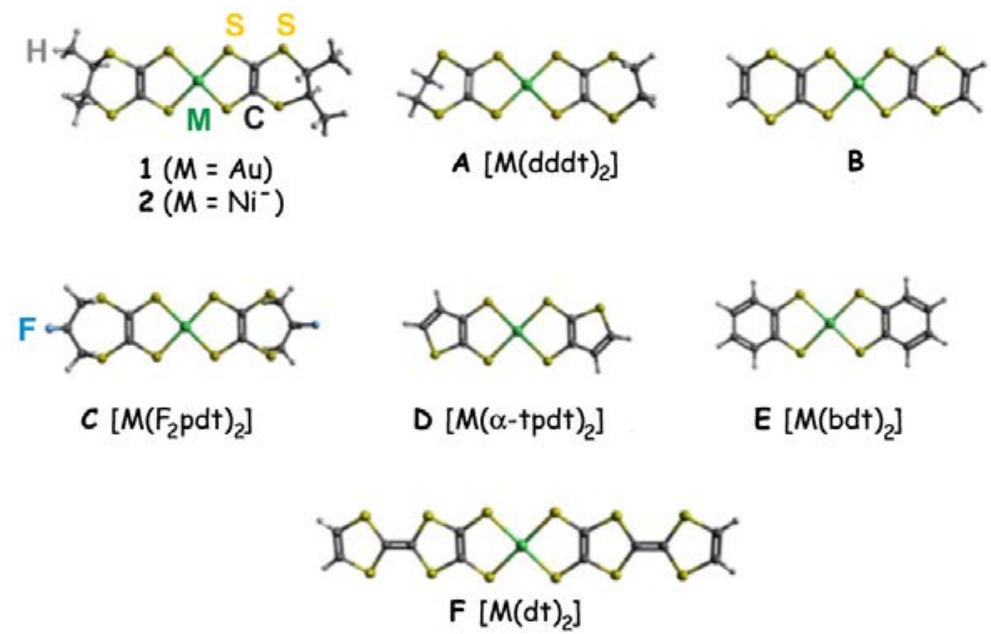

Figure 8. $\left[\mathrm{M}(\mathrm{DT})_{2}\right]^{\mathrm{n}}(\mathrm{M}=\mathrm{Au}, \mathrm{n}=0$ or $\mathrm{Ni}, \mathrm{n}=-1)$ compounds considered in this work.

Besides optimizing the ground state structure and analyzing the localized vs. delocalized character of the unpaired electron, we have also calculated the energy for points along two distortion coordinates shown in Figure 9 in which we fix the $\mathrm{C}-\mathrm{C}$ distances of the two $\mathrm{C}=\mathrm{C}$ double bonds, in one case in a symmetric way, that is, both $\mathrm{C}=\mathrm{C}$ bond lengths are made longer/shorter at the same time, while in the other case the two $\mathrm{C}=\mathrm{C}$ bond lengths are changed in an asymmetric way, that is, when one is made shorter by a given amount, the other is made longer by exactly the same amount. All the other molecular coordinates are being optimized for each fixed pair of $\mathrm{C}=\mathrm{C}$ distances without imposing any additional restriction. To do this, we first calculate the energy for the symmetric mode to find the most stable symmetric structure for each compound and then we take this minimum energy symmetric structure as the origin for the asymmetric mode. For asymmetric compounds the energy difference between the minimum energy asymmetric structure and the reference minimum energy symmetric structure represents the energy barrier for intermolecular electron transfer.
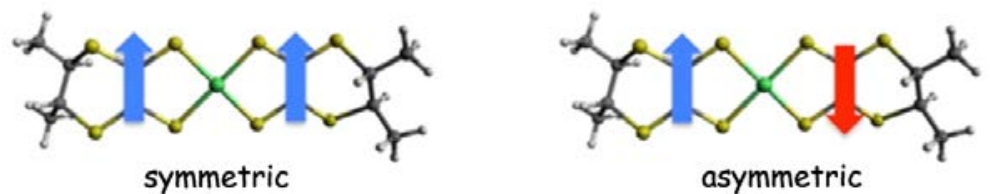

Figure 9. Symmetric and asymmetric distortion modes for the $\left[\mathrm{M}(\mathrm{DT})_{2}\right]$ compounds studied.

The main results of this study are the following: (i) a symmetric structure was found to be the most stable for all $\left[\mathrm{Ni}(\mathrm{DT})_{2}\right]^{-}$compounds, and (ii) an asymmetric structure was found to be energetically more favorable for all $\left[\mathrm{Au}(\mathrm{DT})_{2}\right]$ compounds, except $\mathbf{E}$ and $\mathbf{F}$, both exhibiting a more extended delocalization. In Table S8 (see SI) we have gathered the main geometric parameters for the optimized structures found for the five asymmetric and two symmetric 
$\left[\mathrm{Au}(\mathrm{DT})_{2}\right]$ compounds as well as the seven symmetric $\left[\mathrm{Ni}(\mathrm{DT})_{2}\right]^{-}$compounds. In all cases a practically perfect square planar coordination geometry is found for the metal atoms.
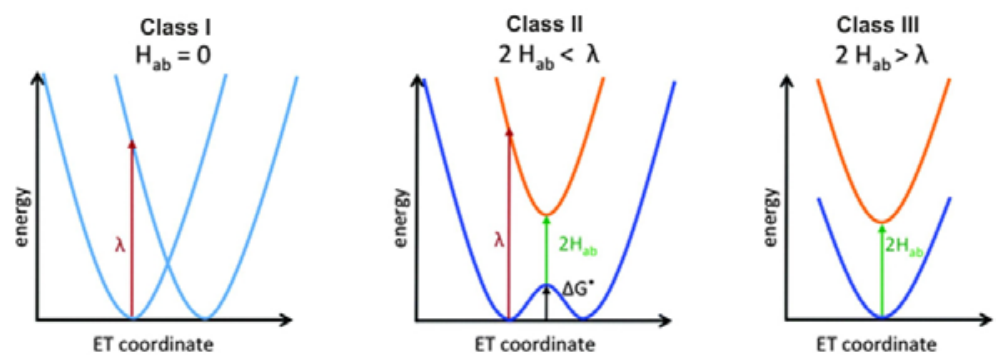

Figure 10. Potential energy curves for the three primary Robin-Day classes: class I (left), class II (middle) and class III (right).

What can we learn from these results? According to the classification of Robin and Day for mixed valence compounds, ${ }^{42,43}$ for an $\left[\mathrm{M}(\mathrm{DT})_{2}\right]$ system like 1a-b, with one electron which may be localized on one dithiolene ligand (DT) or delocalized over the two ligands, there are three different possibilities, schematically shown in Figure 10 where the energy of two possible states (·DT-M-DT and DT-M-DT·) is plotted as a function of a reaction coordinate describing the electron transfer (ET) process from one dithiolene ligand to the other one. Class I compounds occur when the electronic coupling $\left(2 \mathrm{H}_{\mathrm{ab}}\right)$ between the two ligands is very weak or nil so that there are two decoupled diabatic redox states and fully localized redox centers (Figure 10 left). When the strength of the electronic coupling between the centers increases, there are two different possibilities. If the coupling is moderate so that $2 \mathrm{H}_{\mathrm{ab}}$ is sizeable yet smaller than the so-called Marcus reorganization energy $\lambda$ (i.e. a vertical reorganization energy, covering the associated structural reorganization, solvent effects, etc.), there occurs a double-well adiabatic ground state with partially localized charges and a barrier for thermal electron transfer (Class II compounds, Figure 10 middle). Finally, in the case of a strong coupling such that $2 \mathrm{H}_{\mathrm{ab}} \geq \lambda$, only a single ground state minimum occurs without ET barrier where the electron is delocalized over the two dithiolene ligands (Class III compounds, Figure 10 right). The problem is thus to understand when a $\left[\mathrm{M}(\mathrm{DT})_{2}\right]\left(\mathrm{M}=\mathrm{Au}, \mathrm{Ni}^{-}\right)$system, potentially interesting as a single component molecular conductor, may be considered as Class II or Class III. According to the model in Figure 10 the two basic parameters needed to think about this question are the reorganization energy $\lambda$ of each dithiolene ligand and the electronic coupling $2 \mathrm{H}_{\mathrm{ab}}$ between them. 


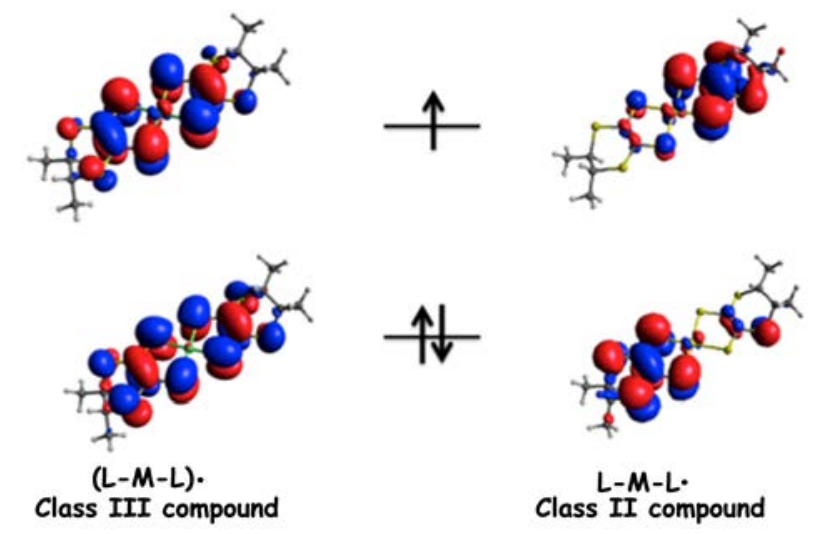

Figure 11. Highest occupied molecular orbitals for the symmetric Class III compound [Ni(dm-dddt) $]_{2}^{-}$(left) and the asymmetric class II compound [Au(dm-dddt) ${ }_{2}$ (right).

Before looking for a simple way to evaluate the relative strength of these two parameters it will be helpful to briefly consider the problem from a molecular orbital perspective. As shown in Figure 11, the SOMO of $\left[\mathrm{M}(\mathrm{DT})_{2}\right]$ will be essentially built from a combination of two ligand $\pi$-type ( $\mathrm{C}=\mathrm{C}$ bonding/ $\mathrm{C}-\mathrm{S}$ antibonding) orbitals, each one centered on a single dithiolene unit. If the coupling between these orbitals is strong, as for Class III compounds, we have a symmetric structure in which the two fragment orbitals are equal and their in- and out-of-phase combinations will be completely delocalized over the molecule, as shown in the left side of Figure 11. In contrast, a weak coupling between these fragment orbitals will lead to an asymmetric Class II compound, where the lower-lying in-phase combination will be mostly localized on the fragment with shorter $\mathrm{C}=\mathrm{C} /$ longer $\mathrm{C}-\mathrm{S}$ distances and the out-of-phase combination will be mostly localized on the fragment with longer $\mathrm{C}=\mathrm{C} /$ shorter $\mathrm{C}-\mathrm{S}$ distances, as shown in the right part of Figure 11. The coupling of the right and left fragment orbitals is mediated by the $\mathrm{d}_{\mathrm{xz}}$ orbital of the metal atom (we use a local system of axis such that the inner core of the molecule lies in the xy plane with $\mathrm{x}$ being the longer axis of the molecule) which is the orbital that can interact with the $\pi$-type orbital of the dithiolene fragment.

Coming back to the attempt to estimate the tendency toward an intramolecular localization, the two parameters we need to evaluate are the reorganization energy $\lambda$ of each dithiolene ligand upon electron transfer and the electronic coupling $2 \mathrm{H}_{\mathrm{ab}}$ between them. In our case, the reorganization energy, mostly related to the stretching of the $\mathrm{C}=\mathrm{C}$ bond, will depend on the structure of the dithiolene ligand, but at a first sight we should not expect large differences for most of the compounds shown in Figure 8, except probably for those provided with extended delocalization. An accurate calculation of $\lambda$ for each case is difficult, since one has to decide the charge assigned to an isolated dithiolene fragment, which is not an obvious task and even if this question can be solved, it is not clear why the reorganization energy calculated for an 
isolated dithiolene should be a good representation of the reorganization of the same dithiolene unit within the DT-M-DT compound. In fact there is no need for an accurate absolute value of $\lambda$ since we are more interested in obtaining just some qualitative guidelines to compare the situation in different compounds, so that a practical solution is to use the changes in energy for the symmetric distortion (Figure 9) where the value of the $\mathrm{C}=\mathrm{C}$ bond distance of the two $\mathrm{C}=\mathrm{C}$ bonds simultaneously changes to get an idea on the energy involved in this $\mathrm{C}=\mathrm{C}$ stretching.
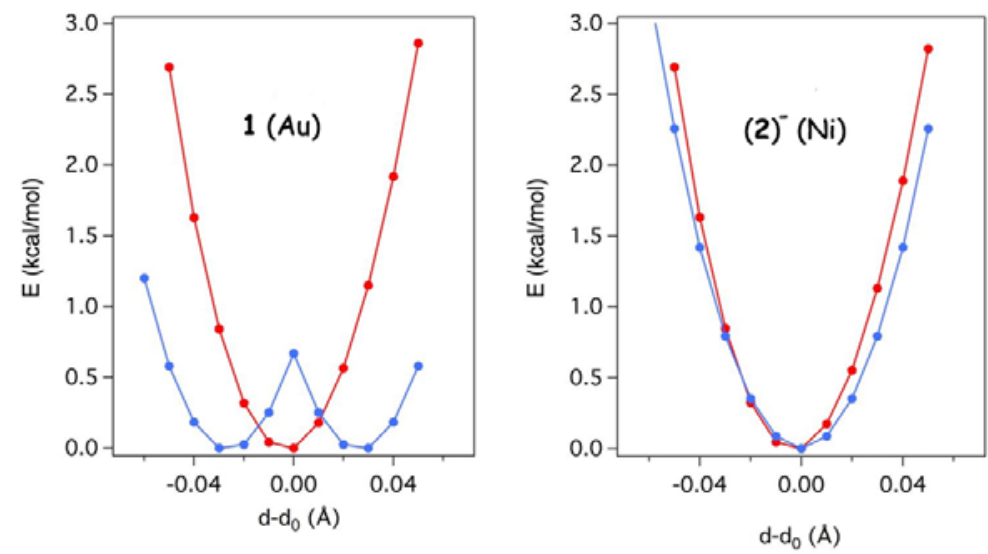

Figure 12. Potential energy curves for the symmetric (red) and asymmetric (blue) distortion modes of 1 and (2)

As can be seen in Figure 12 for $\left[\mathrm{Au}(\mathrm{dm}-\mathrm{dddt})_{2}\right](\mathbf{1})$ and $\left[\mathrm{Ni}(\mathrm{dm}-\mathrm{dddt})_{2}\right]^{-}\left(\mathbf{2}^{-}\right)$, the energy vs. $\mathrm{d}_{\mathrm{C}=\mathrm{C}}$ curve for the symmetric mode is well described by an harmonic potential, $\mathrm{E}\left(\mathrm{d}-\mathrm{d}_{\mathrm{o}}\right)=\mathrm{k}(\mathrm{d}-$ $\left.d_{o}\right)^{2}$, and we will use the harmonic force constant $(k)$ as a measure of the reorganization energy for the different compounds. The values obtained by fitting the calculated $E v s .\left(d-d_{0}\right)$ curve for the symmetric mode for all studied compounds can be found in the last column of Table 4. In general, the value for $\mathrm{k}$ is in the range $40-60 \mathrm{eV} \cdot \AA^{-2}$, with small differences between similar compounds. For a given dithiolene ligand the value of $\mathrm{k}$ calculated for the [Au(DT $)_{2}$ ] compound is somewhat larger (between 1 and 16\%, taking the value for [Au(DT) $\left.)_{2}\right]$ as a reference) than for the corresponding $\left[\mathrm{Ni}(\mathrm{DT})_{2}\right]^{-}$compound.

Table 4. Energy difference $(\Delta \mathrm{e})$ for the two molecular orbitals in Figure 11 and harmonic force constant (k) for the symmetric mode in Figure 9 calculated for different $\left[\mathrm{M}(\mathrm{DT})_{2}\right](\mathrm{M}=\mathrm{Au}, \mathrm{Ni})$ systems

\begin{tabular}{|c|c|c|c|c|c|}
\hline system & $\Delta \mathbf{e}(\mathrm{eV})$ & $\boldsymbol{k}\left(\mathrm{kcal} \cdot \mathrm{mol}^{-1 \cdot} \AA^{-2}\right)$ & system & $\Delta \mathbf{e}(\mathrm{eV})$ & $\boldsymbol{k}\left(\mathrm{kcal} \cdot \mathrm{mol}^{-1} \AA^{-2}\right)$ \\
\hline $\mathbf{1}(\mathrm{Au})$ & 1.26 & 52.6 & $(2)^{-}(\mathrm{Ni})$ & 1.65 & 47.8 \\
\hline $\mathbf{A}(\mathrm{Au})$ & 1.24 & 54.9 & $(\mathbf{A})^{-}(\mathrm{Ni})$ & 1.63 & 45.9 \\
\hline
\end{tabular}




\begin{tabular}{|c|c|c|c|c|c|}
\hline system & $\Delta \mathbf{e}(\mathrm{eV})$ & $\boldsymbol{k}\left(\mathrm{kcal} \cdot \mathrm{mol}^{-1} \AA^{-2}\right)$ & system & $\Delta \mathbf{e}(\mathrm{eV})$ & $\boldsymbol{k}\left(\mathrm{kcal} \cdot \mathrm{mol}^{-1} \AA^{-2}\right)$ \\
\hline $\mathbf{B}(\mathrm{Au})$ & 1.11 & 51.0 & $(\mathbf{B})^{-}(\mathrm{Ni})$ & 1.55 & 50.7 \\
\hline $\mathbf{C}(\mathrm{Au})$ & 1.48 & 50.8 & $(\mathbf{C})^{-}(\mathrm{Ni})$ & 1.88 & 49.3 \\
\hline $\mathbf{D}(\mathrm{Au})$ & 1.42 & 51.9 & $(\mathbf{D})^{-}(\mathrm{Ni})$ & 1.72 & 50.3 \\
\hline $\mathbf{E}(\mathrm{Au})$ & 1.48 & 46.0 & $(\mathbf{E})^{-}(\mathrm{Ni})$ & 1.83 & 42.1 \\
\hline $\mathbf{F}(\mathrm{Au})$ & 0.99 & 58.8 & $(\mathbf{F})^{-}(\mathrm{Ni})$ & 1.17 & 49.8 \\
\hline
\end{tabular}

The value of the second parameter, the electronic coupling $2 \mathrm{H}_{\mathrm{ab}}$ between the two interacting $\pi$ ligand orbitals, has been approximated by evaluating the orbital energy difference for closed shell systems with either two or four electrons occupying the pair of molecular orbitals of Figure 11, considering the minimum energy symmetric structure for each compound (in that way we avoid the ambiguity in choosing between the energies of the $\alpha$ and $\beta$ spin-orbitals to evaluate the splittings since the actual molecules bear a single unpaired electron and an unrestricted approach is needed for the calculations). Since similar conclusions can be reached using either of the two series of energy differences, only the values obtained with two electrons in the lower orbital and none in the upper one are reported in Table 4. These values are found to be in the range $1-2 \mathrm{eV}$. The magnitude of this splitting depends mainly on two parameters, the energy match and the overlap between the $d_{x z}$ orbital of the metal and the $\pi$ type ligand orbital. The values in Table 4 indicate that for a given ligand, the splitting for the $\left[\mathrm{Ni}(\mathrm{DT})_{2}\right]^{-}$compound is considerably larger than for the $\left[\mathrm{Au}(\mathrm{DT})_{2}\right]$ one, with an average difference of about $0.4 \mathrm{eV}$. The only exception is $\mathbf{F}$ for which the difference between the $\mathrm{Ni}$ and $\mathrm{Au}$ cases is significantly smaller $(0.18 \mathrm{eV})$. In this case the ligand is considerably more extended than in the other cases, so that simply because of the normalization condition, the weight of the orbital at the interacting $S$ atoms is noticeably smaller, thus leading to a weaker interaction and a smaller difference between the Au and Ni cases. For a same metal atom, the variation of the splitting with the ligand is smaller. For the gold compounds most of the splittings are in the range 1.2-1.4 eV, except for $\mathbf{F}$, which has a significantly smaller one of $0.99 \mathrm{eV}$, for the same reason pointed above.

Considering all these results together it seems quite clear that, at least for the [M(DT) $)_{2}$ compounds of interest to build single component molecular conductors, the leading factor in deciding whether a given compound will have a symmetric (class III) or asymmetric (class II) structure depends mainly on the electronic coupling term. The $\left[\mathrm{Au}(\mathrm{DT})_{2}\right]$ systems have a clear bias for asymmetric structures except when there occurs an extended delocalization (in these 
cases the ligand reorganization also plays a role favoring the symmetric structure). In contrast, the larger coupling mediated by the nickel atom leads invariably to a symmetric structure for the $\left[\mathrm{Ni}(\mathrm{DT})_{2}\right]^{-}$compounds. This conclusion is reinforced when looking at the values gathered in Table 5 for the five $\left[\mathrm{Au}(\mathrm{DT})_{2}\right]$ compounds with an asymmetric structure. Taking into account the approximate nature of our evaluation, it is clear that, as expected, the height of the barrier separating the two equivalent asymmetric structures $(\Delta \mathrm{E})$ decreases as the electronic coupling increases.

Table 5. $\mathrm{C}=\mathrm{C}$ in the minimum energy symmetric and asymmetric structures together with the energy barrier for the interconversion as well as $\Delta \mathrm{e}$ and $\boldsymbol{k}$ values for the five compounds with an asymmetric structure

\begin{tabular}{|c|c|c|c|c|c|}
\hline system & $\mathbf{C}_{-} \mathbf{C}_{\text {sym }}(\AA)$ & $\Delta \mathbf{e}(\mathrm{eV})$ & $\boldsymbol{k}\left(\mathrm{eV}^{-2}\right)$ & $\mathbf{C}^{-C_{\text {asym }}(\AA)}$ & $\Delta \mathbf{E}(\mathrm{kcal} / \mathrm{mol})$ \\
\hline $\mathbf{1}(\mathrm{Au})$ & $1.37 / 1.37$ & 1.26 & 52.6 & $1.34 / 1.40$ & 0.67 \\
\hline $\mathbf{A}(\mathrm{Au})$ & $1.37 / 1.37$ & 1.24 & 54.9 & $1.34 / 1.40$ & 0.66 \\
\hline $\mathbf{B}(\mathrm{Au})$ & $1.36 / 1.36$ & 1.11 & 51.0 & $1.34 / 1.38$ & 0.78 \\
\hline $\mathbf{C}(\mathrm{Au})$ & $1.37 / 1.37$ & 1.48 & 50.8 & $1.35 / 1.39$ & 0.38 \\
\hline $\mathbf{D}(\mathrm{Au})$ & $1.39 / 1.39$ & 1.42 & 51.9 & $1.37 / 1.41$ & 0.25 \\
\hline
\end{tabular}

C. Role of the intermolecular interactions in the solid. At this point one could raise the following objection: why does compound $\mathbf{C}(\mathrm{Au})$ which, with a seven-membered ring in the ligand, ${ }^{14}$ is not that different from compounds $\mathbf{1}(\mathrm{Au})$ or $\mathbf{A}(\mathrm{Au})$, exhibit a symmetric structure in the solid in contrast with the asymmetric ones found for $\mathbf{1}(\mathrm{Au})$ or $\mathbf{A}(\mathrm{Au})$ ? In addition, although the crystal structure of the good conductor $\mathbf{D}(\mathrm{Au})$ is not known, ${ }^{12}$ several strongly related systems recently studied by Lorcy and coworkers are also symmetric. ${ }^{15}$ Is there something wrong in the previous analysis? It could be argued that, according to Table 5 , these two systems $\mathbf{C}$ and $\mathbf{D}$ are also those having a smaller bias for the asymmetric structure. However we strongly believe that there are more stringent reasons directing the reversal of the preference. So far we have purposely restricted our attention to isolated molecules but, as we will see below, intermolecular interactions in the solid can provide a strong driving force towards a symmetric structure. Note that in the following discussion we use the labeling "symmetric” or "asymmetric” to designate Class III and Class II molecules, respectively. Of course, a "symmetric" Class III molecule in the solid may be slightly asymmetric because of 
some asymmetric distribution of molecules around but this kind of asymmetry only slightly alters the essentially symmetric nature of the SOMO of a Class III molecule.

Let us consider $\mathbf{C}(\mathrm{Au})$ for which, because of the segregation effect of the fluorine atoms, the crystal structure contains chains of this molecule. If we assume that the individual molecules are asymmetric, as our calculations suggest, since the unpaired electron is located in one of the two ligands, we can consider the molecule as a dipole. If we now try to make a chain with these dipoles, we will end up with situations like those in Figure 13a, exhibiting a head-to-tail type overlap between successive units, simply because of electrostatic reasons. In that case, the SOMO electrons cannot see each other and consequently, there is no stabilization through band formation. In contrast, if the molecule is symmetric (Figure 13b), there is a considerable SOMO $\cdots$ SOMO interaction in both arrangements leading to a sizeable stabilization because of band formation. Consequently, if the shape of $\left[\mathrm{M}(\mathrm{DT})_{2}\right]$ drives the molecules toward a crystal structure containing chains with good intermolecular overlaps, the system will tend to be symmetric even if, as in the case of $\mathbf{C}(\mathrm{Au})$, the isolated molecules may have a preference for an asymmetric structure.

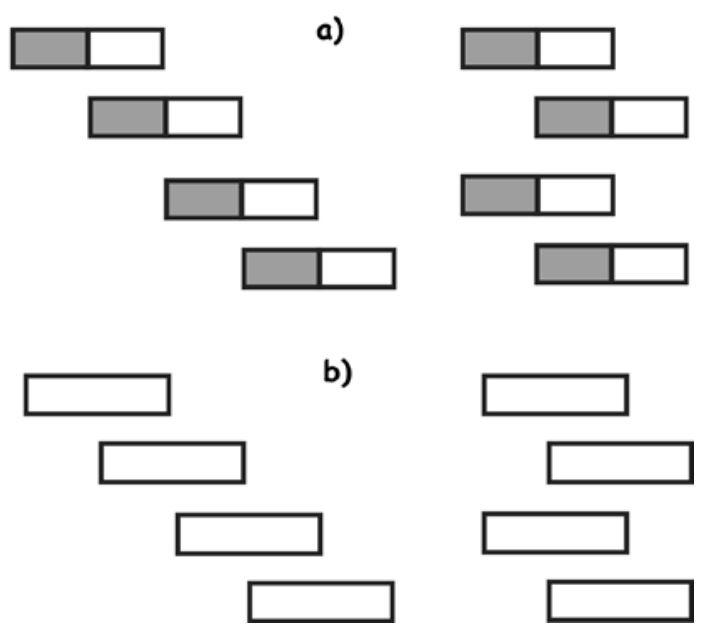

Figure 13. Schematic representation of one-dimensional stackings of (a) asymmetric $\left[\mathrm{M}(\mathrm{DT})_{2}\right]$ molecules with a localized SOMO and of (b) symmetric $\left[\mathrm{M}(\mathrm{DT})_{2}\right]$ molecules with a delocalized SOMO. The drawings are purely schematic without any reference to the real intermolecular overlap.

If the molecule is asymmetric and its shape is such that it does not favor the formation of $\left[\mathrm{M}(\mathrm{DT})_{2}\right]$ chains with good intermolecular overlaps which will become the building units of the solid, then the system will try to find the best way to arrange the dipole-like units compatible with the molecular shape. The simplest case is a packing of dimeric units as in $\left[\mathrm{Au}(\mathrm{dddt})_{2}\right] \mathbf{A}^{30}{ }^{30}$ Depending on the shape and substituents the system will search for two- or three-dimensional structures as it is the case for $\left[\mathrm{Au}(\mathrm{dm} \text {-dddt })_{2}\right] \mathbf{1}$. 
In view of these considerations we can distinguish three groups of $\left[\mathrm{Au}(\mathrm{DT})_{2}\right]$ single molecule solids (in the following we use the term "chain" to refer to "chains with good intermolecular overlaps”):

(A) Systems without ligand extended delocalization exhibiting chains in the crystal structure. These molecules will adopt a symmetric structure and undergo sizeable SOMO $\cdots$ SOMO interactions and consequently they will lead to good conductors. For each case it will depend on the relative value of the band dispersion and on-site repulsion if the system exhibits a metallic or some kind of antiferromagnetic ground state. But even in the last case, the transition to a metallic state will be often possible by applying pressure. This is for instance the case of the series of compounds recently developed by Lorcy and coworkers. ${ }^{15}$

(B) Systems with ligand extended delocalization. These systems will always be symmetric but depending on the nature of the substituents the transport properties will change. If the shape allows the chain formation we are exactly in the same situation as in the previous case. If the substituents do not allow the formation of chains, because of the symmetric character of the SOMO it will depend on the bulkiness of the outer substituents that SOMO $\cdots$ SOMO interactions along the solid can be established or not. If it is possible, the transport properties will be again as in case $\mathrm{A}$. An example of an $\left[\mathrm{Au}(\mathrm{DT})_{2}\right]$ system of this type exhibiting competition between antiferromagnetic and metallic properties is $\left[\mathrm{Au}(\mathrm{tmdt})_{2}\right] .{ }^{6}$ If substituents are too bulky, the SOMO $\cdots$ SOMO interactions will be weak and the solid will be a magnetic insulator.

(C) Systems without ligand extended delocalization for which chain formation in the crystal structure is not favored. These systems will be asymmetric, they will undergo weak SOMO $\cdots$ SOMO interactions and consequently they will be insulators, as in the case of $\left[\mathrm{Au}(\mathrm{dm}-\mathrm{dddt})_{2}\right] \mathbf{1}$ or $\left[\mathrm{Au}(\mathrm{dddt})_{2}\right] \mathbf{A}^{30}$

Of course, the previous classification should simply be taken as a convenient general organizing principle. The detailed electronic structure and hence the transport properties for each particular case can only be fully understood after a careful analysis of the details of the crystal structure. For instance, a system with chains like those at the right of Figure 13b (i.e., a type A situation) may be either a metal/antiferromagnetic system as discussed above or a diamagnetic semiconductor, depending if the chain is uniform or if it shows some kind of dimerization. Important aspects as the possible two-band behavior through the overlap between the SOMO and SOMO-1 bands have already been shown to play a role in some of 
these systems ${ }^{15 a}$ and thus should also be taken into account. Clearly, a rich materials science of these systems is probably still uncovered.

\section{CONCLUSIONS}

Enantiopure anionic and neutral nickel and gold bis(dithiolene) complexes based on the chiral dithiolene ligand 5,6-dimethyl-5,6-dihydro-1,4-dithiin-2,3-dithiolate (dm-dddt) as (S,S) or $(R, R)$ enantiomers have been synthesized and characterized by $\mathrm{CD}$, electrochemistry and single crystal X-ray diffraction analysis. The long range separation of the anions in (TBA)[Ni(dm-dddt $\left.)_{2}\right]$ results in a semiconducting behavior with poor room temperature conductivity and high activation energy, together with magnetic susceptibility following a Curie-Weiss behavior expected for localized spins. On the other hand, [Au(dm-dddt $\left.)_{2}\right]$ represent the first chiral single component conductors, with semiconducting behavior well explained by band structure calculations, and room temperature conductivity strongly enhanced by applying hydrostatic pressure.

A most surprising feature has been found in the structure of the neutral radical gold complexes $\left[\mathrm{Au}(\mathrm{dm} \text {-dddt })_{2}\right]$, which show a pronounced dissymmetry between the two dithiolene moieties independent of the temperature, also previously noticed in the case of the achiral analogue $\left[\mathrm{Au}(\mathrm{dddt})_{2}\right]$ but not further investigated. Nevertheless, [Au(dm-dddt $\left.)_{2}\right]$ represent the first chiral single component conductor, with semiconducting behavior well explained by band structure calculations and room temperature conductivity strongly enhanced under hydrostatic pressure. A thorough theoretical study conducted on a series of neutral radical gold and anionic radical nickel bis(dithiolene) complexes reported in the literature allowed us to rationalize the intrinsic nature of the dithiolenes dissymmetry in neutral gold complexes together with the symmetry in anionic nickel counterparts, in agreement with our experimental findings. On the basis of the electron coupling between the dithiolene moieties mediated by the metal ion, it can be safely concluded that neutral gold complexes with dithiolene ligands without extended conjugation, i.e. aromatic or TTF backbones, are Class II compounds in the Robin and Day classification, while anionic nickel complexes belong to the Class III thanks to the large electron coupling.

However, the intrinsic tendency toward localization or delocalization is not the only factor to which one should pay attention in trying to design new single component conductors based on metal bis(dithiolene) complexes of this family. The organization of individual molecules in the solid state plays also an influential role. For instance, neutral gold complexes with 
intrinsic asymmetry in the gas phase can show symmetric structures when formation of chains in the solid state is favored. Consequently, SOMO $\cdots$ SOMO interactions in these systems should be strong leading to good conducting properties, as experimentally observed. On the contrary, when the complexes do not adopt a chain-like structure, as is the case with $\left[\mathrm{Au}(\mathrm{dddt})_{2}\right]$ and our enantiopure compounds $\left[\mathrm{Au}(\mathrm{dm} \text {-dddt })_{2}\right]$, they preserve their asymmetry leading to weak SOMO‥SOMO interactions and poor conductivity. This unprecedented experimental and theoretical study sheds new insights on the very important family of single component conductors based on metal bis(dithiolene) complexes.

\section{EXPERIMENTAL SECTION}

Materials and Instrumentation. Unless mentioned otherwise, all reactions were carried out in inert atmosphere, in Schlenk tubes. All the chemicals were purchased from commercial sources and were used as received. The precursors, $(S, S)$ - and $(R, R)$-5,6-dimethyl-5,6dihydro-1,3-dithiolo-1,4-dithiin-2-one 3 were prepared as described in the literature. ${ }^{21,31}$ Elemental (C, H and N) analyses were performed on a Thermo-Scientific Flash 2000 Organic Elemental Analyzer. The IR spectra were recorded on ATR BRUKER VERTEX 70 spectrophotometer in the $4000-400 \mathrm{~cm}^{-1}$ range. MALDI- TOF and ESI MS spectra were recorded on a Bruker Biflex-IIITM (equipped with a $337 \mathrm{~nm} \mathrm{N_{2 }}$ laser) and a Bruker Esquire 3000 plus apparatus, respectively. UV-Vis spectra were recorded in solution using a Lambda 19 PERKIN ELMER Spectrometer. Circular dichroism spectra were recorded using spectrometric grade solvents in a $1 \mathrm{~cm}$ cell at sample concentrations of $10^{-5}$ to $5 \cdot 10^{-5} \mathrm{M}$ using a Jasco J-815 Spectropolarimeter.

Syntheses. $\left[(n-B u)_{4} N\right]\left[A u((S, S)-d m-d d d t)_{2}\right](T B A)(1 a)$. In a Schlenk tube, 0.16 mmol (37.8 $\mathrm{mg}$ ) of $(S, S)-3$ and $0.4 \mathrm{mmol}(21.6 \mathrm{mg})$ of $\mathrm{CH}_{3} \mathrm{ONa}$ in dry methanol were reacted to form the $\mathrm{Na}_{2}((S, S)$-dm-dddt) salt. The complexation was achieved by adding $0.08 \mathrm{mmol}(30.2 \mathrm{mg})$ of $\mathrm{K}\left[\mathrm{AuCl}_{4}\right]$ to the mixture and stirring for several hours. Then, $0.08 \mathrm{mmol}$ (25.8 $\left.\mathrm{mg}\right)$ of [(n$\left.\mathrm{Bu})_{4} \mathrm{~N}\right] \mathrm{Br}$ was added and left to stir for an additional hour. The solution was concentrated to give a light brown solid. The product was dried and purified by repeated precipitations from $\mathrm{CH}_{2} \mathrm{Cl}_{2}$ solution with hexane (34 mg, 50\% yield). Off-white needle shaped crystals suitable for single crystal X-ray analysis were obtained by slow diffusion of hexane into a $\mathrm{CH}_{2} \mathrm{Cl}_{2}$ 
solution. MS (ESI-MS): m/z (M-TBA) $612.81\left(\mathrm{M}_{\mathrm{th}}=612.87\right) ;(\mathrm{M}+\mathrm{TBA}) 1096.89\left(\mathrm{M}_{\mathrm{th}}=\right.$ 1097.44). Elemental analysis calcd. (\%) for $\mathrm{C}_{28} \mathrm{H}_{52} \mathrm{AuNS}_{8}$ : C 39.28, $\mathrm{H}$ 6.12, $\mathrm{Au}$ 23.01, $\mathrm{N}$ 1.64, S 29.96; found: C 39.51, H 6.04, N 1.58, S 30.13.

$\left[(n-B u)_{4} N\right]\left[A u((R, R)-d m-d d d t)_{2}\right](T B A)(\mathbf{1 b})$. Using the same quantities and procedure starting with the $(R, R)$ enantiomer of 3 yielded $31 \mathrm{mg}$ of complex (TBA)(1b) (45\% yield). Elemental analysis calcd. (\%) for $\mathrm{C}_{28} \mathrm{H}_{52} \mathrm{AuNS}_{8}$ : C 39.28, H 6.12, Au 23.01, N 1.64, S 29.96; found: C 39.47, H 6.01, N 1.69, S 30.18.

$\left[(n-B u)_{4} N\right]\left[N i((S, S)-d m-d d d t)_{2}\right](T B A)(2 a)$. In a Schlenk tube, $0.2 \mathrm{mmol}(47.2 \mathrm{mg})$ of $(S, S)-3$ was treated with $0.5 \mathrm{mmol}(26.9 \mathrm{mg})$ of $\mathrm{CH}_{3} \mathrm{ONa}$ in dry methanol to generate the $\mathrm{Na}_{2}((S, S)$ dm-dddt) salt. After 30 minutes of stirring $0.1 \mathrm{mmol}(23.7 \mathrm{mg})$ of $\mathrm{NiCl}_{2} \cdot 6 \mathrm{H}_{2} \mathrm{O}$ was added to the clear orange solution, and let stirring an additional 2 hours, after which $0.1 \mathrm{mmol}$ (32.2 $\mathrm{mg})$ of $\left[(n-\mathrm{Bu})_{4} \mathrm{~N}\right] \mathrm{Br}$ were introduced to the mixture. According to previous reported studies on similar systems, a mixture of dianionic $\left[(n-\mathrm{Bu})_{4} \mathrm{~N}\right]_{2}\left[\mathrm{Ni}((S, S)-\mathrm{dm}-\mathrm{dddt})_{2}\right]$ and monoanionic $\left[(n-\mathrm{Bu})_{4} \mathrm{~N}\right]\left[\mathrm{Ni}((S, S)-\mathrm{dmddt})_{2}\right]$ complexes is obtained, so in order to avoid the expected separation difficulties, the mixture was allowed to stir in open air for an hour to promote the oxidation from (2a) ${ }^{2-}$ to (2a) $)^{-}$. The solvent was reduced under pressure and the pure product was obtained as a green solid by recrystallization from a $\mathrm{CH}_{2} \mathrm{Cl}_{2} / \mathrm{Et}_{2} \mathrm{O}$ mixture (46 mg, 64\% yield). Suitable crystals for single crystal X-ray diffraction studies were grown by slow diffusion of hexane into a $\mathrm{CH}_{2} \mathrm{Cl}_{2}$ solution of the product. MS (ESI-MS): m/z (M-TBA) $473.49\left(\mathrm{M}_{\mathrm{th}}=473.84\right)$; $(\mathrm{M}+\mathrm{TBA}) 957.95\left(\mathrm{M}_{\mathrm{th}}=958.41\right)$. Elemental analysis calcd. $(\%)$ for $\mathrm{C}_{28} \mathrm{H}_{52} \mathrm{NNiS}_{8}$ : C 46.85, H 7.30, N 1.95, Ni 8.18, S 35.73; found: C 46.68, H 7.14, N 2.01, S 35.98.

$\left[(n-B u)_{4} N\right]\left[N i((R, R)-d m-d d d t)_{2}\right](T B A)(2 b)$. Using the $(R, R)$ enantiomer of 3 and following the same procedure lead to the formation of complex (TBA)(2b) (48 mg, 67\% yield). Elemental analysis calcd. (\%) for $\mathrm{C}_{28} \mathrm{H}_{52} \mathrm{NNiS}_{8}$ : C 46.85, H 7.30, N 1.95, Ni 8.18, S 35.73; found: C 46.62, H 7.18, N 2.05, S 35.92.

$\left[\mathrm{Au}((\mathrm{R}, \mathrm{R})-d m-d d d t)_{2}\right](\mathbf{1 b}) .15 .7 \mathrm{mg}$ of $\left[(n-\mathrm{Bu})_{4} \mathrm{~N}\right] \mathrm{AuBr}_{2},{ }^{44}$ a supporting electrolyte which was successfully used in electrocrystallization experiments with [Ni(dddt $\left.)_{2}\right]{ }^{45}$ were dissolved in $24 \mathrm{~mL}$ of nitrobenzene, methylene chloride and acetonitrile mixture (3:2:1, v:v:v). Half of this solution was poured in the cathodic compartment of an electrocrystallization cell, and the 
other half was used to dissolve $15 \mathrm{mg}$ of (TBA)(1b) and placed in the second compartment. The electrochemical oxidation occurred under a constant current of $0.7 \mu \mathrm{A}$. After several days black crystals of $\mathbf{1 b}$ formed on the platinum electrode were collected, washed and dried. MS (MALDI-TOF) m/z: $613.0\left(\mathrm{M}_{\mathrm{th}}=612.87\right)$.

$\left[N i((R, R)-d m-d d d t)_{2}\right](2 \boldsymbol{b}) .37 .6 \mathrm{mg}$ of $\left[(n-\mathrm{Bu})_{4} \mathrm{~N}\right] \mathrm{AuBr}_{2}$ were dissolved in $24 \mathrm{~mL}$ of 1,1,2trichloroethane and acetonitrile mixture (1:5, v:v). The solution was divided in two, and half was used to dissolve $30 \mathrm{mg}$ of $(\mathrm{TBA})(\mathbf{2 b})$. The solutions were placed in the two compartments of an electrocrystallization cell. A constant current of $0.7 \mu \mathrm{A}$ was applied and thin plate shaped crystals formed on the Pt anode after one week. MS (MALDI-TOF) m/z: $473.9\left(\mathrm{M}_{\mathrm{th}}=473.84\right)$.

X-Ray Structure Determinations. Details about data collection and solution refinement are given in Table 6. X-ray diffraction measurements were performed on a Bruker Kappa CCD diffractometer for operating with a Mo-K $\alpha(\lambda=0.71073 \AA)$ X-ray tube with a graphite monochromator. The structures were solved (SHELXS-97) by direct methods and refined (SHELXL-97) by full-matrix least-square procedures on $\mathrm{F}^{2} .{ }^{46}$ All non-H atoms of the donor molecules were refined anisotropically, and hydrogen atoms were introduced at calculated positions (riding model), included in structure factor calculations but not refined. Crystallographic data for the structures have been deposited in the Cambridge Crystallographic Data Centre. CCDC reference numbers: CCDC 1471691 for (TBA)(1a), CCDC 1471692 for (TBA)(2a), CCDC 1471693 for $\mathbf{1 b}$ and CCDC 1471694 for 2b. These data can be obtained free of charge from The Cambridge Crystallographic Data Centre via www.ccdc.cam.ac.uk/data_request/cif.

Table 6. Crystallographic data, details of data collection and structure refinement parameters

\begin{tabular}{ccccc}
\hline $\begin{array}{c}\text { Compound } \\
\text { Chemical formula }\end{array}$ & $\begin{array}{c}\text { (TBA)(1a) } \\
\mathrm{C}_{28} \mathrm{H}_{52} \mathrm{AuNS}_{8}\end{array}$ & $\begin{array}{c}\text { (TBA)(2a) } \\
\mathrm{C}_{28} \mathrm{H}_{52} \mathrm{NNiS}_{8}\end{array}$ & $\begin{array}{c}\mathbf{1 b} \\
\mathrm{C}_{12} \mathrm{H}_{16} \mathrm{AuS}_{8}\end{array}$ & $\begin{array}{c}\mathbf{2} \mathbf{b} \\
{ }_{12} \mathrm{H}_{16} \mathrm{NiS}_{8}\end{array}$ \\
\hline Formula weight $(\mathrm{g} / \mathrm{mol})$ & 856.15 & 717.90 & 613.69 & 475.44 \\
Crystal system & triclinic & triclinic & triclinic & triclinic \\
Space group & $P 1$ & $P 1$ & $P 1$ & $P 1$ \\
$a(\AA)$ & $10.1007(8)$ & $9.9946(6)$ & $6.957(5)$ & $6.9784(4)$ \\
$b(\AA)$ & $12.8982(7)$ & $12.8908(12)$ & $7.938(5)$ & $7.8994(6)$ \\
$c\left(^{\AA}\right)$ & $15.4354(15)$ & $15.4197(13)$ & $9.378(5)$ & $9.2170(5)$ \\
$\alpha\left(^{\circ}\right)$ & $81.816(6)$ & $81.690(6)$ & $73.394(5)$ & $70.105(6)$ \\
$\beta\left(^{\circ}\right)$ & $80.903(9)$ & $80.294(5)$ & $74.625(5)$ & $75.451(5)$ \\
$\gamma\left({ }^{\circ}\right)$ & $70.138(6)$ & $69.818(6)$ & $73.189(5)$ & $75.277(4)$ \\
\hline
\end{tabular}




\begin{tabular}{|c|c|c|c|c|}
\hline Volume $\left(\AA^{3}\right), \mathrm{Z}$ & 1859.0(3), 2 & 1830.0(3), 2 & 465.6(5), 1 & 454.44(5), 1 \\
\hline Temperature (K) & 293(2) & 293(2) & $250(2)$ & 293(2) \\
\hline Calculated density ( $\left.\mathrm{Mg} \mathrm{m}^{-3}\right)$ & 1.530 & 1.303 & 2.189 & 1.737 \\
\hline Flack parameter & $-0.048(9)$ & $-0.013(19)$ & $0.021(18)$ & $0.017(12)$ \\
\hline Absorption coefficient $\left(\mathrm{mm}^{-1}\right)$ & 4.425 & 1.005 & 8.785 & 1.975 \\
\hline \multirow{2}{*}{ Final R indices $[I>2 \sigma(I)]$} & $\mathrm{R} 1=0.0379$ & $\mathrm{R} 1=0.0450$ & $\mathrm{R} 1=0.0454$ & $\mathrm{R}_{1}=0.0267$ \\
\hline & $\mathrm{wR} 2=0.0641$ & $\mathrm{wR} 2=0.0871$ & $\mathrm{wR} 2=0.0625$ & $\mathrm{wR}_{2}=0.0576$ \\
\hline \multirow{2}{*}{$R$ indices (all data) } & $\mathrm{R} 1=0.0854$ & $\mathrm{R} 1=0.0936$ & $\mathrm{R} 1=0.0784$ & $\mathrm{R}_{1}=0.0415$ \\
\hline & $\mathrm{wR} 2=0.0793$ & $\mathrm{wR} 2=0.1068$ & $\mathrm{wR} 2=0.0678$ & $\mathrm{wR}_{2}=0.0610$ \\
\hline Goodness-of-fit on $F^{2}$ & 1.027 & 1.020 & 1.010 & 1.019 \\
\hline
\end{tabular}

Single crystal conductivity measurements. Electrical resistivity was measured on needleshaped single crystals of (TBA)(2a), (TBA)(2b), 1a and 1b. Gold contacts were first evaporated on the crystals and gold wires were glued with silver paste on those contacts. Due to high values of resistance under ambient conditions, the resistivity for (TBA)(2a) and (TBA)(2b) was measured in two points, applying a constant voltage of $5 \mathrm{~V}$ and measuring the current using a Keithley 6487 Picoammeter / Voltage Source. Resistivity measurements on 1a and 1b single crystals were also performed in two points because of the size and the brittleness of the needles. Ambient pressure experiments were performed with dc currents in the range 0.1-1 $\mu \mathrm{A}$, while a low frequency $(<100 \mathrm{~Hz}$ ) lock-in amplifier technique applying an alternative current in the range $0.1-1 \mu \mathrm{A}$ was used for high pressure experiments.

For 1a crystals, resistivity measurements were also performed under high hydrostatic pressure in a CuBe clamped cell up to 12 kbar with silicon oil (Daphne 7373) as the pressure transmitting medium. The pressure at room temperature was extracted from the resistance of a manganin gauge in the pressure cell and it is this value that is indicated in the figures. However, the loss of pressure during cooling is estimated to 2 kbar. A copper-constantan thermocouple inside the pressure cell was used as the thermometer. Resistivity measurements were performed in the range 15 - $300 \mathrm{~K}$ using a cryocooler equipment.

Computational details. The tight-binding band structure calculations were of the extended Hückel type. ${ }^{47} \mathrm{~A}$ modified Wolfsberg-Helmholtz formula was used to calculate the nondiagonal $\mathrm{H}_{\mu \nu}$ values. ${ }^{48}$ All valence electrons were taken into account in the calculations and the basis set consisted of Slater-type orbitals of double- $\zeta$ quality for Au $5 d$ and of single- $\zeta$ quality for $\mathrm{Au} 6 \mathrm{~s}$ and 6p, $\mathrm{C} 2 \mathrm{~s}$ and 2p, S 3s and 3p and $\mathrm{H} 1 \mathrm{~s}$. The ionization potentials, contraction coefficients and exponents were taken from previous work. ${ }^{14}$ 
The DFT calculations for isolated molecular systems were carried out according to the prescription of Kaupp et al. ${ }^{49}$ for the study of organic mixed-valence compounds. We refer the reader to this work for an excellent and very detailed discussion of the warnings and requirements for the application of DFT methods to mixed valence molecules. Since we are interested in obtaining a qualitative description of the intrinsic preference for a localized vs. delocalized nature of the ground state of metal dithiolenes, we have disregarded environmental effects. All calculations have been done with the Gaussian 09 program $^{50}$ using the hybrid blyp35 functional proposed by Kaupp et al. ${ }^{49}$ together with the double- $\xi$ quality LANL2DZ basis set and the Los Alamos effective core potentials. ${ }^{51}$

First-principles periodic calculations for the solid were performed using a numerical atomic orbitals DFT ${ }^{52}$ approach developed for efficient calculations in large systems and implemented in the SIESTA code. ${ }^{53,54,55}$ The generalized gradient approximation to DFT and, in particular, the functional of Perdew, Burke, and Ernzerhof (PBE) ${ }^{56}$ has been used in these calculations. In order to study the relative energies of states with localized electrons band calculations for a proper supercell containing two molecules have been undertaken, including a Hubbard correction term $\mathrm{U}_{\text {eff }}=\mathrm{U}-\mathrm{J}=4.0 \mathrm{eV}$ for the $\mathrm{S}(3 \mathrm{p})$ and Au (5d) states. ${ }^{57}$ We have found that this $U$ term on $S$ is needed for accurately describing the electronic structure of TTF-TCNQ and related molecular solids were accurate experimental information on the bandwidth and charge transfer is available. The contribution of core electrons in these calculations has been described by norm-conserving Troullier-Martins pseudo-potentials, ${ }^{58}$ factorized in the Kleinman-Bylander form. ${ }^{59}$ Valence electrons were treated explicitly using a split-valence basis set of double- $\xi$ plus polarization functions for S, C, and $\mathrm{H}$ atoms obtained with an energy shift of $10 \mathrm{meV} \cdot{ }^{60}$ For gold atoms we have used a split-valence basis set of double- $\xi$ plus polarization quality, where the $5 \mathrm{~d}$ electrons of Au were treated also as valence electrons. The basis functions used for Au have been optimized in order to reproduce the geometry and the bulk modulus for the ccp crystal structure of metallic gold. ${ }^{61}$ The energy cutoff for the real space integration mesh was set to $350 \mathrm{Ry}$ and the Brillouin zone was sampled using a mesh with 8x8x8 k-points obtained using the method of Monkhorst and Pack. $^{62}$ These calculations were performed using the experimental crystal structure.

\section{ASSOCIATED CONTENT}

Supporting Information. Full experimental section including description of the synthesis and characterization of all new materials and all the techniques employed in the research 
reported here. This information is available free of charge via the internet at http://pubs.acs.org.

\section{AUTHOR INFORMATION}

\section{Corresponding Authors}

p.alemany@ub.edu

canadell@icmab.es

narcis.avarvari@univ-angers.fr

\section{Notes}

The authors declare no competing financial interest.

\section{ACKNOWLEDGMENTS}

This work was supported in France by the National Agency for Research (ANR Inter, ANR12-IS07-0004-04, CREMM Project), the Region Pays de la Loire (grant for D.B.), the CNRS, the University of Angers, the University of Bordeaux and the Aquitaine Region. Work in Spain was supported by the Spanish Ministerio de Economía y Competitividad (Grants FIS2012-37549-C05-05, FIS2015-64886-C5-4-P and CTQ2015-64579-C3-3-P) and Generalitat de Catalunya (2014SGR301 and XRQTC). E.C. acknowledges support of the Spanish MINECO through the Severo Ochoa Centers of Excellence Program under Grant SEV-2015-0496. 
For table of contents graphic

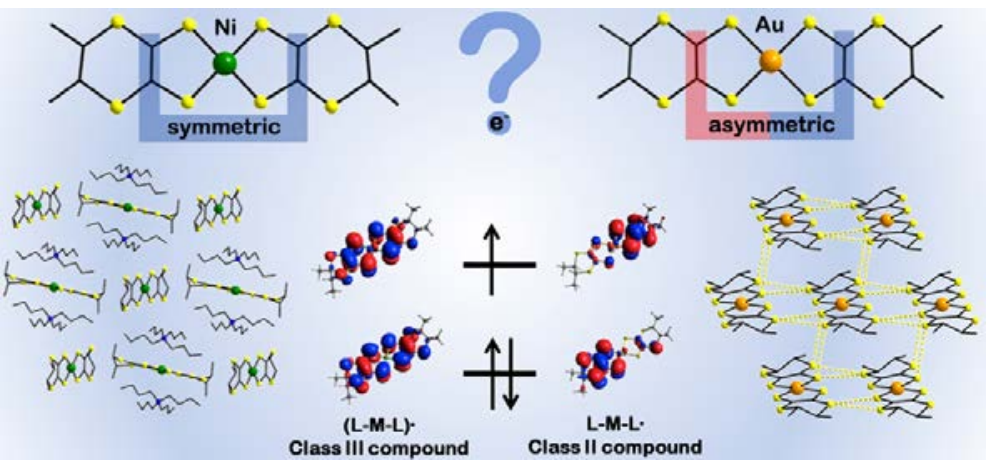




\section{References}

(1) Robertson, N.; Cronin, L. Coord. Chem. Rev. 2002, 227, 93-127.

(2) (a) Kato, R. Chem. Rev. 2004, 104, 5319-5346. (b) Kato, R. Bull. Chem. Soc. Jpn. 2014, 87, 355-374.

(3) Bousseau, M.; Valade, L.; Legros, J.-P.; Cassoux, P.; Carbauskas, M.; Interrante, L. V. J. Am. Chem. Soc. 1986, 108, 1908-1916.

(4) Kobayashi, A.; Fujiwara, E.; Kobayashi, H. Chem. Rev. 2004, 104, 5243-5264.

(5) (a) Tanaka, H.; Okano, Y.; Kobayashi, H.; Suzuki, W.; Kobayashi, A. Science 2001, 291, 285-287. (b) Tanaka, H.; Tokumoto, M.; Ishibashi, S.; Graf, D.; Choi, E. S.; Brooks, J. S.; Yasuzuka, S.; Okano, Y.; Kobayashi, H.; Kobayashi, A. J. Am. Chem. Soc. 2004, 126, 10518-10519.

(6) (a) Suzuki, W.; Fujiwara, E.; Kobayashi, A.; Fujishiro, Y.; Nishibori, E.; Takata, M.; Sakata, M.; Fujiwara, H.; Kobayashi, H. J. Am. Chem. Soc. 2003, 125, 1486-1487. (b) Zhou, B.; Shimamura, M.; Fujiwara, E.; Kobayashi, A.; Higashi, T.; Nishibori, E.; Sakata, M.; Cui, H.; Takahashi, K.; Kobayashi, H. J. Am. Chem. Soc. 2006, 128, 38723873.

(7) Zhou, B.; Idobata, Y.; Kobayashi, A.; Cui, H.-B.; Kato, R.; Takagi, R.; Miyagawa, K.; Kanoda, K. J. Am. Chem. Soc. 2012, 134, 12724-12731.

(8) Cui, H.; Kobayashi, H.; Ishibashi, S.; Sasa, M.; Iwase, F.; Kato, R.; Kobayashi, A. J. Am. Chem. Soc. 2014, 136, 7619-7622.

(9) Llusar, R.; Uriel, S.; Vicent, C.; Clemente-Juan, J. M.; Coronado, E.; Gómez-Garcia, C. J.; Braïda, B.; Canadell, E. J. Am. Chem. Soc. 2004, 126, 12076-12083.

(10) Cui, H.; Tsumuraya, T.; Miyazaki, T.; Y. Okano, Y.; Kato, R. Eur. J. Inorg. Chem. 2014, 3837-3840.

(11) Schiødt, N. C.; Bjørnholm, T.; Bechgaard, K.; Neumeier, J. J.; Allgeier, C.; Jacobsen, C. S.; Thorup, N. Phys. Rev. B 1996, 53, 1773-1778.

(12) Belo, D.; Alves, H.; Lopes, E. B.; Duarte, M. T.; Gama, V.; Henriques, R. T.; Almeida, M.; Pérez-Benítez, A.; Rovira, C.; Veciana, J. Chem. Eur. J. 2001, 7, 511-519.

(13) Higashino, T.; Jeannin, O.; Kawamoto, T.; Lorcy, D.; Mori, T.; Fourmigué, M. Inorg. Chem. 2015, 54, 9908-9913.

(14) Dautel, O. J.; Fourmigué, M.; Canadell, E.; Auban-Senzier, P. Adv. Funct. Mater. 2002, 12, 693-698. 
(15) (a) Tenn, N.; Bellec, N.; Jeannin, O.; Piekara-Sady, L.; Auban-Senzier, P.; Íñiguez, J.; Canadell, E.; Lorcy, D. J. Am. Chem. Soc. 2009, 131, 16961-16974. (b) Yzambart, G.; Bellec, N.; Nasser, G.; Jeannin, O.; Roisnel, T.; Fourmigué, M.; Auban-Senzier, P.; Íñiguez, J.; Canadell, E.; Lorcy, D. J. Am. Chem. Soc. 2012, 134, 17138-17148.

(16) (a) Coronado, E.; Day, P. Chem. Rev. 2004, 104, 5419-5448. (b) Lorcy, D.; Bellec, N.; Fourmigué, M.; Avarvari, N. Coord. Chem. Rev. 2009, 253, 1398-1438.

(17) Wagnière, G. H. On Chirality and the Universal Asymmetry, Wiley-VCH, Weinheim, 2007.

(18) (a) Rikken, G. L. J. A.; Fölling, J.; Wyder, P. Phys. Rev. Lett. 2001, 87, 236602-1-4. (b) Krstić, V.; Roth, S.; Burghard, M.; Kern, K.; Rikken, G. L. J. A. J. Chem. Phys. 2002, $117,11315-11319$.

(19) Pop, F.; Auban-Senzier, P.; Canadell, E.; Rikken, G. L. J. A.; Avarvari, N. Nat. Commun. 2014, 5, 3757, DOI: 10.1038/ncomms4757.

(20) Avarvari, N.; Wallis, J. D. J. Mater. Chem. 2009, 19, 4061-4076.

(21) (a) Réthoré, C.; Avarvari, N.; Canadell, E.; Auban-Senzier, P.; Fourmigué, M. J. Am. Chem. Soc. 2005, 127, 5748-5749. (b) Madalan, A. M.; Réthoré, C.; Fourmigué, M.; Canadell, E.; Lopes, E. B.; Almeida, M.; Auban-Senzier, P.; Avarvari, N. Chem. Eur. J. 2010, 16, 528-537. (c) Pop, F.; Auban-Senzier, P.; Frąckowiak, A.; Ptaszyński, K.; Olejniczak, I.; Wallis, J. D.; Canadell, E.; Avarvari, N. J. Am. Chem. Soc. 2013, 135, 17176-17186.

(22) Biet, T.; Fihey, A.; Cauchy, T.; Vanthuyne, N.; Roussel, C.; Crassous, J.; Avarvari, N. Chem. Eur. J. 2013, 19, 13160-13167.

(23) (a) Danila, I.; Riobé, F.; Piron, F.; Puigmartí-Luis, J.; Wallis, J. D.; Linares, M.; Ågren, H.; Beljonne, D.; Amabilino, D. B.; Avarvari, N. J. Am. Chem. Soc. 2011, 133, 83448353. (b) Danila, I.; Pop, F.; Escudero, C.; Feldborg, L. N.; Puigmartí-Luis, J.; Riobé, F.; Avarvari, N.; Amabilino, D. B. Chem. Commun. 2012, 48, 4552-4554. (c) Pop, F.; Melan, C.; Danila, I.; Linares, M.; Beljonne, D.; Amabilino, D. B.; N. Avarvari, N. Chem. Eur. J. 2014, 20, 17443-17453.

(24) Perochon, R.; Poriel, C.; Jeannin, O.; Piekara-Sady, L.; Fourmigué, M. Eur. J. Inorg. Chem. 2009, 5413-5421.

(25) (a) Debnath, S.; Bergamini, J.-F.; Artzner, F.; Mériadec, C.; Camerel, F.; Fourmigué, M. Chem. Commun. 2012, 48, 2283-2285. (b) Mebrouk, K.; Debnath, S.; Fourmigué, M.; Camerel F. Langmuir 2014, 30, 8592-8597. 
(26) Le Gal, Y.; Vacher, A.; Dorcet, V.; Fourmigué, M.; Crassous, J.; Lorcy, D. New J. Chem. 2015, 39, 122-129.

(27) Kisch, H.; Eisen, B.; Dinnebier, R.; Shankland, K.; David, W. I. F.; Knoch, F. Chem. Eur. J. 2001, 7, 738-748.

(28) Lieffrig, J.; Jeannin, O.; Auban-Senzier, P.; Fourmigué, M. Inorg. Chem. 2012, 51, $7144-7152$.

(29) Dunitz, J. D.; Karrer, A.; Wallis, J. D. Helv. Chim. Acta 1986, 69, 69-70.

(30) Schultz, A. J.; Wang, H. H.; Soderholm, L. C.; Sifter, T. L.; Williams, J. M.; Bechgaard, K.; Whangbo, M.-H. Inorg. Chem. 1987, 26, 3757-3761.

(31) Matsumiya, S.; Izuoka, A.; Sugawara, T.; Taruishi, T.; Kawada, Y. Bull. Chem. Soc. Jpn. 1993, 66, 513-522.

(32) Pop, F.; Laroussi, S.; Cauchy, T.; Gómez-García, C. J.; Wallis, J. D.; Avarvari, N. Chirality 2013, 25, 466-474.

(33) Lim, B. S.; Fomitchev, D. V.; Holm, R. H. Inorg. Chem. 2001, 40, 4257-4262.

(34) Yang, S.; Pop, F.; Melan, C.; Brooks, A. C.; Martin, L.; Horton, P.; Auban-Senzier, P.; Rikken, G. L. J. A.; Avarvari, N.; Wallis, J. D. CrystEngComm 2014, 16, 3906-3916.

(35) Pop, F.; Batail, P.; Avarvari, N. Crystals 2016, 6, 8, doi:10.3390/cryst6010008.

(36) Atzori, M.; Pop, F.; Auban-Senzier, P.; Clérac, R.; Canadell, E.; Mercuri, M. L.; Avarvari, N. Inorg. Chem. 2015, 54, 3643-3653.

(37) Pop, F.; Lacour, J.; Avarvari, N. Rev. Roum. Chim. 2012, 57, 457-462.

(38) Canadell, E. New. J. Chem. 1997, 21, 1147-1159.

(39) (a) Canadell, E.; Rachidi, I. E.-I.; Ravy, S.; Pouget, J.-P.; Brossard, L.; Legros, J.-P. J. Phys. I, France 1989, 50, 2967-2981. (b) Canadell, E; Ravy, S.; Pouget, J.-P.; Brossard, L. Solid State Comm. 1990, 75, 633-638.

(40) Whangbo, M.-H.; Williams, J. M.; Leung, P. C. W.; Beno, M. A.; Emge, T. J.; Wang, H. H. Inorg. Chem. 1985, 24, 3500-3502.

(41) Rousseau, R.; Gener, M.; Canadell, E. Adv. Funct. Mater. 2004, 14, 201-214.

(42) Robin, M. B.; Day, P. Adv. Inorg. Chem. Radiochem. 1967, 10, $247-422$.

(43) For an excellent discussion of mixed valence compounds see chapter 3 in: Launnay, J.P.; Verdaguer, M. Electrons in Molecules. From basic principles to molecular electronics, Oxford University Press, Oxford, 2014.

(44) Braunstein, P.; Clark, R. J. H. J. Chem. Soc. Dalton Trans. 1973, 1845-1848. 
(45) Kushch, L. A.; Gritsenko, V. V.; Buravov, L. I.; Khomenko, A. G.; Shilov, G. V.; Dyachenko, O. A.; Merzhanov, V. A.; Yagubskii, E. B.; Rousseau, R.; Canadell, E. J. Mater. Chem. 1995, 5, 1633-1638.

(46) Sheldrick, G. M. Programs for the Refinement of Crystal Structures, University of Göttingen: Göttingen, Germany, 1996.

(47) Whangbo, M.-H.; Hoffmann, R. J. Am. Chem. Soc 1978, 100, 6093-6098.

(48) Ammeter, J. H.; Bürgi, H.-B.; Thibeault, J.; Hoffmann, R. J. Am. Chem. Soc. 1978, 100, 3686-3692.

(49) (a) Kaupp. M.; Renz, M.; Parthey, M.; Stolte, M.; Würthner, F.; Lambert, C. Phys. Chem. Chem. Phys. 2011, 13, 16973-16986. (b) Parthey, M.; Kaupp, M. Chem. Soc. Rev. 2014, 43, 5067-5088.

(50) Frisch, M. J. et al., GAUSSIAN 09 (Revision A.2), Gaussian Inc., Wallingfort CT, 2009.

(51) Wadt, W. R.; Hay, P. J. J. Chem. Phys. 1985, 82, 270-283, 284-98, 299-310.

(52) (a) Hohenberg, P.; Kohn, W. Phys. Rev. 1964, 136, B864-B871. (b) Kohn, W.; Sham, L. J. Phys. Rev. 1965, 140, A1133-A1138.

(53) Soler, J. M.; Artacho, E.; Gale, J. D.; García, A.; Junquera, J.; Ordejón, P.; SánchezPortal, D. J. Phys.: Condens. Matter. 2002, 14, 2745-2779.

(54) For more information on the SIESTA code visit: http://departments.icmab.es/leem/siesta/.

(55) For a review on applications of the SIESTA approach in materials science see: SánchezPortal, D.; Ordejón, P.; Canadell, E. Structure and Bonding (Berlin) 2004, 113, 103170.

(56) Perdew, J. P.; Burke, K.; Ernzerhof, M. Phys. Rev. Lett. 1996, 77, 3865-3868.

(57) Dudarev, S. L.; Botton, G. A.; Savrasov, S. Y.; Humphreys, C. J.; Sutton, A. P. Phys. Rev. B 1998, 57, 1505.

(58) Troullier, N.; Martins, J. L. Phys. Rev. B 1991, 43, 1993-2006.

(59) Kleinman, L.; Bylander, D. M. Phys. Rev. Lett. 1982, 48, 1425-1428.

(60) Artacho, E.; Sánchez-Portal, D.; Ordejón, P.; García, A.; Soler, J. M. Phys. Stat. Sol. (b) 1999, 215, 809-817.

(61) Alemany, P.; Llunell, M.; Canadell, E. Theor. Chem. Acc. 2009, 123, 85-92.

(62) Monkhorst, H. J.; Pack, J. D. Phys. Rev. B 1976, 13, 5188-5192. 